OPEN ACCESS

Edited by:

Brian R. Noga,

University of Miami, United States

Reviewed by:

Noriko Hiroi,

Keio University, Japan

Urszula Slawinska,

Nencki Institute of Experimental

Biology, Poland

*Correspondence:

Patrick J. Whelan

whelan@ucalgary.ca

${ }^{\dagger}$ These authors have contributed equally to this work

Specialty section

This article was submitted to

Systems Biology,

a section of the journal

Frontiers in Neuroscience

Received: 08 May 2017 Accepted: 04 October 2017 Published: 18 October 2017

Citation:

Kim LH, Sharma S, Sharples SA,

Mayr KA, Kwok CHT and Whelan PJ

(2017) Integration of Descending

Command Systems for the Generation

of Context-Specific Locomotor

Behaviors. Front. Neurosci. 11:581

doi: 10.3389/fnins.2017.00581

\section{Integration of Descending Command Systems for the Generation of Context-Specific Locomotor Behaviors}

\author{
Linda H. Kim ${ }^{1,2+}$, Sandeep Sharma ${ }^{1,3+}$, Simon A. Sharples ${ }^{1,2}$, Kyle A. Mayr ${ }^{1,2}$, \\ Charlie H. T. Kwok ${ }^{1,3}$ and Patrick J. Whelan ${ }^{1,2,3 *}$ \\ ${ }^{1}$ Hotchkiss Brain Institute, University of Calgary, Calgary, AB, Canada, ${ }^{2}$ Department of Neuroscience, University of Calgary, \\ Calgary, AB, Canada, ${ }^{3}$ Department of Comparative Biology and Experimental Medicine, University of Calgary, Calgary, AB, \\ Canada
}

Over the past decade there has been a renaissance in our understanding of spinal cord circuits; new technologies are beginning to provide key insights into descending circuits which project onto spinal cord central pattern generators. By integrating work from both the locomotor and animal behavioral fields, we can now examine context-specific control of locomotion, with an emphasis on descending modulation arising from various regions of the brainstem. Here we examine approach and avoidance behaviors and the circuits that lead to the production and arrest of locomotion.

Keywords: locomotor behavior, supraspinal, descending, goal-directed, approach, aversion

\section{INTRODUCTION}

Animals produce a wide array of locomotor behaviors in response to internal and external cues. Normally, animals survey the environment in search of appropriate olfaction, audition, visual, or tactile sensory inputs. Internally motivated cues may be due to appetitive drive such as food and reproduction, and other physiological needs like safety, shelter, or adaptation to a new environment. These cues inform ongoing movement sequences by converging onto locomotor

Abbreviations: A10, Dopaminergic cell group A10; A11, Dopaminergic cell group A11; A13, Dopaminergic cell group A13; ABA, Accessory basal amygdala; AMG, Amygdala; BG, Basal ganglia; BLA, Basolateral amygdala complex; CeA, Central nucleus of the amygdala; CeM, Medial central nucleus of the amygdala; ChR2, Channelrhodopsin 2; Chx10, Transcription factor Chx10; CnF, Cuneiform nucleus; D1, Dopamine receptor subtype 1; D2, Dopamine receptor subtype 2; DDS, Diencephalospinal dopamine system (in zebrafish); dlPAG, Dorsolateral periaqueductal gray; DLR, Diencephalic locomotor region; dMSNs, Direct pathway medium spiny neurons; dPAG, Dorsal periaqueductal gray; GABA, gamma-Aminobutyric acid; GAD65, glutamic acid decarboxylase; Gi, Gigantocellular reticular nucleus; GiA, Gigantocellular reticular nucleus alpha part; GiV, Gigantocellular reticular nucleus ventral part; GP, Globus pallidus; GPe, Globus pallidus external; GPi, Globus pallidus internal; iMSNs, Indirect pathway medium spiny neurons; LH, Lateral hypothalamus; Lhx3, Transcription factor Lhx3; IPAG, Lateral periaqueductal gray; LPGi, Lateral paragigantocellular nucleus; MdV, Ventral part of medullary reticular formation; MLR, Mesencephalic locomotor region; MRF, Medullary reticular formation; NAc, Nucleus accumbens; PAG, Periaqueductal gray; PMH, Premammillary nucleus of the hypothalamus; PnC, Pontine reticular nucleus caudal; PnO, Pontine reticular nucleus oral; PPN, Pedunculopontine nuclei; PPTg, Pedunculopontine tegmental nucleus; SC, Superior colliculus; SLR, Subthalamic locomotor region; SN, Substantia nigra; SNc, Substantia nigra pars compacta; SNr, Substantia nigra pars reticulata; STh/ STN, Subthalamic nucleus; V1, Primary visual cortex; V1 L5, Layer 5 of the primary visual cortex; Vglut2, Vesicular glutamate 2; vlPAG, Ventrolateral periaqueductal gray; VMH, Ventromedial hypothalamus; VP, Ventral pallidum; VTA, Ventral tegmental area; ZI, Zona incerta. 
control centers in the brainstem and spinal cord, thus facilitating the generation of context-appropriate locomotor behaviors.

In the first part of this review, we focus on key supraspinal regions for locomotor control, with emphasis placed on how technological advances are beginning to reveal cell types and the underlying functional connectome. In the second part of this review, we will explore the afferent projections to these locomotor regions and discuss how internal and external triggers can drive appetitive (approach) or aversive (avoidance) locomotor responses.

\section{DESCENDING COMMAND SYSTEMS FOR LOCOMOTION}

Over the past 75 years, studies on the descending control of locomotion have been directed toward three regions (Whelan, 1996; Jordan et al., 2008); the Subthalamic Locomotor Region (SLR), the Mesencephalic Locomotor Region (MLR: Figure 1), and the Medullary Reticular Formation (MRF: Figure 1). These regions were initially identified based on their ability to elicit various forms of locomotor behaviors in response to direct electrical stimulation of these regions. The term "locomotor region" was used since electrical stimulation cannot be confined to anatomically-defined nuclei. These regions are conserved across vertebrate species studied (reviews Rossignol et al., 2006; Fetcho et al., 2008; Grillner et al., 2008; Jordan et al., 2008; Ryczko and Dubuc, 2013) with initial experiments being performed in cats (Shik et al., 1969-English translation of their 1966 publication; reviews Armstrong, 1986; Whelan, 1996), later in rats (Mel'nikova, 1975, 1977 as cited by Ross and Sinnamon, 1984; Sinnamon et al., 1984; Skinner and Garcia-Rill, 1984), and recently in mice (Bouvier et al., 2015; Roseberry et al., 2016).

Investigations into the underlying cellular and system mechanisms for the generation of locomotor behaviors begun in tandem with the identification of locomotor regions. Earlier work was performed in relatively simple organisms (Gillette et al., 1978; Olson and Krasne, 1981; Edwards et al., 1999; Esch and Kristan,
2002) and primitive vertebrates (Grillner et al., 2008). Work on the leech, lamprey and xenopus have provided fascinating similarities between swim behaviors and circuit organization of organisms separated by up to 560 million years of evolution (Mullins et al., 2011). Recent advances in molecular biology and genetic tools have enabled the functional connectivity of locomotor circuit elements in mammalian systems to be explored (Bouvier et al., 2015; Roseberry et al., 2016).

\section{THE MEDULLARY RETICULAR FORMATION: A CENTRE FOR LOCOMOTOR STOP AND GO}

The MRF contains groups of diffusely located nuclei that form an important integration center for the control of locomotion, with descending projections onto interneurons and motoneurons of the cervical and lumbar spinal cord (Grillner et al., 1968; Peterson et al., 1979; Bouvier et al., 2015). Shik et al. (1969) were the first to show the existence of a pathway from the MLR to the MRF. Although, activity in the MRF is known to correspond to locomotor activity, recordings from the MRF in freely walking cats showed that activity patterns were complex, as only some units corresponded to the rhythmic electromyographic activity of muscles while others did not (Drew et al., 1986; Perreault et al., 1993). Both electrical and direct drug-based stimulation of the MRF can elicit locomotion (Garcia-Rill and Skinner, 1987a,b; Noga et al., 1988; Jordan, 1998). Similarly, rhythmic patterns or locomotor-like rhythmicity in the isolated in vitro brainstemspinal cord preparation can be evoked (Liu and Jordan, 2005; Hägglund et al., 2010; Kiehn, 2016). Additionally, stimulation of ventrolateral funiculi, containing the reticulospinal projections, can produce bouts of rhythmic motor activity (Magnuson et al., 1995). Acute lesions of this tract eliminate locomotion elicited by stimulation of the MLR in decerebrate cats (Steeves and Jordan, 1980) and result in changes of gait in freely moving animals (Brustein and Rossignol, 1998).

Classically, the MRF has been subdivided into four key nuclei distributed across the medulla and the pons and is also

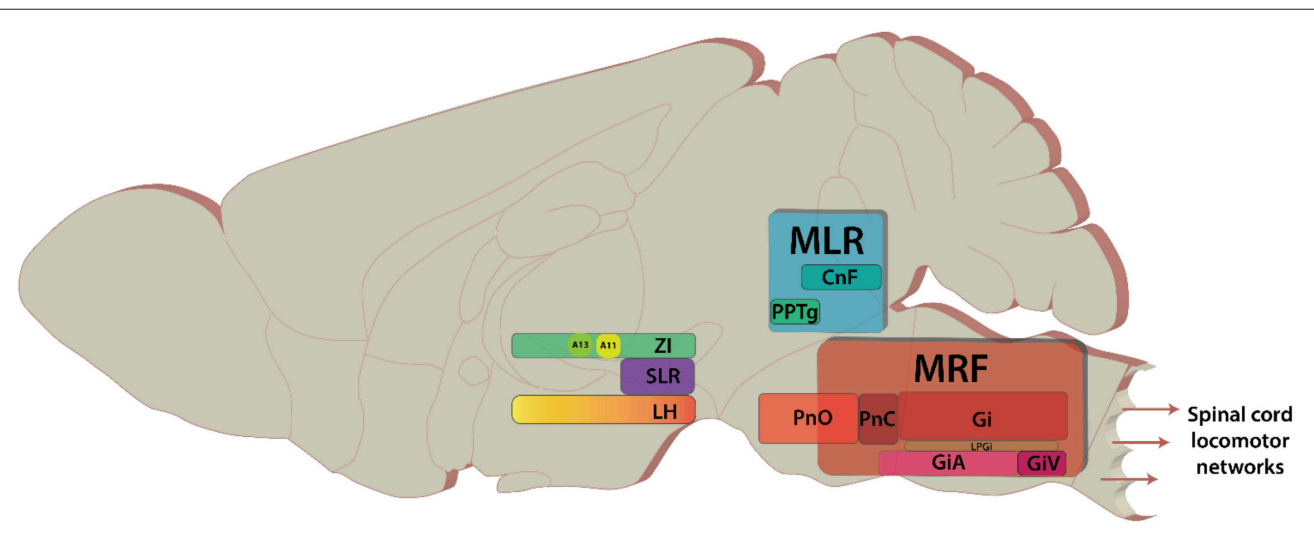

FIGURE 1 | Key areas of the brain discussed in the review. The brain areas are included here have diverse functions in addition to modulating locomotion. Sagittal view of representative locations of locomotor centers. 
known as ponto-medullary reticular formation (review Drew et al., 2004). In rodents, these regions correspond with pontine reticular nucleus oral $(\mathrm{PnO})$ and caudal $(\mathrm{PnC})$, gigantocellular reticular nucleus $(\mathrm{Gi})$, and magnocellular nucleus of medulla which encompasses lateral paragigantocellular nucleus (LPGi), gigantocellular reticular nucleus alpha (GiA), and ventral section (GiV), respectively (Paxinos and Franklin, 2008; Esposito et al., 2014). Recent work has focused on the Gi, LPGi, GiA, and GiV. These nuclei form the reticulospinal pathway, and contain cells that descend ipsilaterally via the ventrolateral and ventromedial funiculi (Petras, 1967; Peterson et al., 1979). Contralateral projections also exist (Jankowska et al., 2003; Krutki et al., 2003; Szokol et al., 2011). Recent work using genetic and intersectional viral tracing has revealed that reticulospinal pathways are more diverse than previously thought, and cells can be organized into clusters based on their projections either in the cervical or lumbar spinal cord (Esposito et al., 2014). The ventral part of the MRF (MdV) was highlighted as a region with functional connectivity to forelimb motor neurons suggesting that MRF regions may be organized somatotopically. Interestingly in cat MRF cells were observed to project over long distances to multiple segments (Matsuyama et al., 1999). These differences may represent the different demands of grasping for rodents compared to cats (Whishaw et al., 2008). However, projections to multiple segments have also been observed in the monkey (Kneisley et al., 1978; Coulter et al., 1979).

Most descending MRF cells are glutamatergic and were traditionally thought to form the excitatory command signal for locomotion. Photostimulation of vesicular glutamate 2 (Vglut2)expressing cells in the brainstem with channelrhodopsin 2 (ChR2) can elicit spinal rhythmicity in vitro (Hägglund et al., 2010). Subsequent investigations explored a subpopulation of glutamatergic cells in the brainstem that can be identified by the Chx10 and Lhx3 transcription factors. These cells express c-fos (a marker of neuronal activation) following bouts of locomotor activity, receive input from the MLR, and project to the cervical spinal cord (Bretzner and Brownstone, 2013). Manipulation of activity of these cells in vivo did not alter locomotor behavior in mice (Bretzner and Brownstone, 2013), however, activation of these cells in zebrafish is sufficient to drive locomotor activity (Kimura et al., 2013). Surprisingly, recent work on the Chx10 population in mice found that activation of this cell-type at the junction between the rostral medulla (rostral Gi) and caudal pons (PnC) disrupted spinallygenerated rhythmicity in vitro, and caused the animal to stop when activated in vivo (Bouvier et al., 2015). Recruitment of spinally-located premotor inhibitory interneurons by the Chx10 MRF neurons was implicated (Bouvier et al., 2015). Conversely, stop commands in fish (Wannier et al., 1995) and tadpoles (Boothby and Roberts, 1992; Perrins et al., 2002; Li et al., 2003) are reported to be mediated by descending inhibitory cells of the MRF, which project mono-synaptically to motoneurons and are triggered by sensory afferents in the head. This poses an interesting possibility for a parallel stopping mechanism in mammals that remains to be discovered (review Klemm, 2001). Indeed, a GABAergic/glycinergic projection from the MRF to the spinal cord exists in rodents but its function in locomotor control remains unknown (Holstege, 1991).

In addition to the glutamatergic and GABAergic/glycinergic descending pathways within the brainstem are several monoaminergic neuromodulatory pathways that can modulate locomotor activity. The major descending brainstem modulatory pathways are the serotonergic raphespinal pathway and the noradrenergic coeruleospinal pathways. These systems have been reviewed elsewhere (Jordan et al., 2008). Recent work suggests that monoamines (5-HT and noradrenaline) increase in concentration many seconds before locomotion and decrease gradually to baseline once locomotion is terminated. These long timeframes suggest that monoamines are not involved in moment-to-moment modulation of spinal cord circuits and may possibly be released extrasynaptically (Noga B. R. et al., 2017).

\section{THE MESENCEPHALIC LOCOMOTOR REGION: AN INTEGRATIVE HUB FOR LOCOMOTOR SPEED AND GAIT}

The MLR is located on the mesopontine border and comprises of the cuneiform $(\mathrm{CnF})$ and the pedunculopontine nuclei (PPN) (Figure 1). In basal vertebrates, the MLR comprises the laterodorsal tegmental nucleus and the PPN. In mammals, it comprises the PPN, but also the CnF (Ryczko and Dubuc, 2013, 2017). It can be described as a classical region for locomotor control. Electrical stimulation of the mesopontine border with increasing intensity led to a serial progression from walking to running to galloping (Shik et al., 1969). Initially it was thought that the MLR projects serially to the MRF and acts as a "volumecontrol" for locomotion, as ablation of the MRF abolished MLRevoked responses in the spinal cord (Noga et al., 2003). Since the original finding the location of the nuclei comprising the MLR and its projections have been steadily refined.

The PPN, referred to as the pedunculopontine tegmental nucleus (PPTg) in rodents (Paxinos and Franklin, 2008) and sometimes the nucleus tegmenti pedulculopontinus in humans (Schaltenbrand and Wahren, 1977), is located in the ventrolateral portion of the MLR (Olszewski and Baxter, 1954). It is composed of cells with heterogeneous neurotransmitter phenotypes including but not limited to: GABA, glutamate, acetylcholine, and calcium-binding proteins and neuropeptides (Clements and Grant, 1990; Lavoie and Parent, 1994; Fortin and Parent, 1999; Vincent, 2000; Mena-Segovia et al., 2008, 2009). There is no doubt that the use of different terms has led to confusion in the field. In this review we will refer to the PPTg when discussing rodent relevant papers and PPN when referring to cat, monkey, or human work. In terms of projections, the PPN and $\mathrm{CnF}$ connect to sensorimotor, associative, and limbic areas of the basal ganglia and the thalamus in monkeys and humans (Sébille et al., 2017). Analysis of these projections suggests that the PPN may integrate sensorimotor, cognitive, and emotional information. The anterior part of the PPN may be related to motor control in the monkey. In contrast, the $\mathrm{CnF}$ connectome is more restricted involving predominantly limbic brain regions (Sébille et al., 2017). Some reports have identified 
the PPTg as an effective site for evoking locomotion, and direct efferent projections to the lumbar spinal cord have been reported (Skinner et al., 1990). Of the two regions, stimulation of the $\mathrm{CnF}$ appears to be more robust in driving locomotion in the cat (Shik and Orlovsky, 1976-original article in Russian: Sirota and Shik, 1973). The CnF lies dorsal to PPTg and borders the inferior colliculi ventrally (Allen Brain Atlas: https://tinyurl.com/ $\mathrm{k} 8 \mathrm{~g} 98 \mathrm{tl})$. Like the PPTg, the $\mathrm{CnF}$ is composed of heterogenous cell types including GABAergic (Ford et al., 1995), glutamatergic (Heise and Mitrofanis, 2006), peptidergic (Sar et al., 1978; Beitz, 1982a,b) cells with some cholinergic neurons (Ford et al., 1995).

Recent work examined MLR cell types for their roles in locomotor behaviors (Roseberry et al., 2016; Kroeger et al., 2017; Mena-Segovia and Bolam, 2017). Activity of the glutamatergic MLR cells correlate with spontaneous locomotor episodes and their activation is sufficient to produce locomotor bouts. Conversely, activity of the GABAergic population is associated with stationary states and their activation stops locomotion, partly through suppression of the local MLR glutamatergic population (Roseberry et al., 2016). This suggests that GABAergic and glutamatergic MLR cells collectively control decelerating and accelerating locomotor behaviors. Work in cats shows that the substantia nigra pars reticulata $(\mathrm{SNr})$ projects to the PPN and suppresses muscle tone while another projection from the lateral $\mathrm{SNr}$ to the $\mathrm{CnF}$ promotes locomotor activity (Takakusaki et al., 2003). It is thought that the cholinergic MLR population modulates locomotion, but activation of these cells is not sufficient to elicit a locomotor bout. Instead, stimulation of cholinergic MLR cells leads to acceleration of locomotion (Roseberry et al., 2016). However, there are interspecies differences in the density of cholinergic cells. For example, in Parkinsonian patients where the number of cholinergic cells in the PPN are reduced (Hirsch et al., 1987; Jellinger, 1988; Zweig et al., 1989), gait disturbances are often observed (reviews Pahapill and Lozano, 2000; Alam et al., 2011). In addition, basal ganglia afferent connectivity onto the PPN, and from the PPN onto the basal ganglia differ between species. This may help explain the uncertainty in the efficacy of deep brain stimulation stimulation in Parkinson's patients (Alam et al., 2011). Some studies have reported beneficial effects but other studies are less supportive. There is a debate about whether stimulation is targeting the PPN, with the most effective site being slightly posterior to the PPN, in the $\mathrm{CnF}$ and the subCnF (Ferraye et al., 2010). Notably the location of the nuclei encompassing the MLR is still a matter of debate, and there appears to be interspecies differences (for details refer to Alam et al., 2011, 2013; Liang et al., 2011, 2012; Thankachan et al., 2012; Ryczko and Dubuc, 2013; Xiang et al., 2013; Sherman et al., 2015). The $\mathrm{CnF}$ is an important part of MLR in higher mammals such as cats and monkeys, whereas the precuneiform nucleus ( $\mathrm{PrCnF})$ is the mouse analog of $\mathrm{CnF}$. In mice the PrCnF projects directly to the spinal cord (Liang et al., 2011, 2012). This is not the case in the cat where the $\mathrm{CnF}$ was found to project to the first cervical segment. Likewise, in monkeys, the $\mathrm{CnF}$ projects ipsilaterally within segments of the spinal cord. An additional complexity in interpreting the literature is that the size of the $\mathrm{PrCnF}$ in cats (Satoda et al., 2002) and possibly monkeys (Castiglioi et al., 1978) is likely underestimated as the boundaries between the $\operatorname{PrCnF}$ and $\mathrm{CnF}$ in cats are not as distinct (Liang et al., 2011).

To summarize, the MLR is well-studied, but comparing and contrasting studies, especially between species can be difficult. Generally speaking, in rodents, the data suggest that the PPTg (PPN) is better associated with reward-based motor behaviors, place preference, and sensorimotor gating, than locomotion (Koch et al., 1993; Inglis et al., 1994; Olmstead and Franklin, 1994; Alam et al., 2011). On the other hand, the $\mathrm{CnF}$ and PrCnF seem to be better associated with locomotion (Garcia-Rill and Skinner, 1987a; Milner and Mogenson, 1988; Noga B. et al., 2017).

\section{THE DIENCEPHALON: A HUB FOR GOAL-DIRECTED LOCOMOTION}

The diencephalon is home to several regions that can elicit locomotion. Although, diencephalic sites have been described in several species, they have been named differently based on the differences in anatomy and effective sites for stimulation. A region of the diencephalon that was pro-locomotory was first described in the cat in the 1930's (Ectors et al., 1938; Masserman, 1938), and electrical stimulation of the subthalamic region was conducted by Waller (1940). Additional work in the 1980s from Orlovsky, Sinnamon, and Mori amongst others provided new insight into areas within the posterior hypothalamus, lateral hypothalamus, and zona incerta that could elicit locomotor activity. While differences were observed, a general finding was in freely moving animals, it was found that an initial scan of the area was performed before exploratory activity was initiated (Mori et al., 1989). These behaviors are often indistinguishable from spontaneous locomotor behavior (Grossen and Kelley, 1972; Leppänen et al., 2006; Lamprea et al., 2008).

Initial reports suggested the site for eliciting locomotion in the cat was the subthalamic nucleus (STN) (abbreviated as STh in rodents); and thus, it was named the subthalamic locomotor region (SLR) (Grossman, 1958; Kaelber and Smith, 1979). Work conducted later in the rat found that the zona incerta (or "zone of uncertainty" dorsal to STh) and medial lateral hypothalamus $(\mathrm{LH})$ had lower thresholds for electrical stimulation (Figure 1; Sinnamon and Stopford, 1987; Milner and Mogenson, 1988; Sinnamon, 1993). In the lamprey, this region is known as the diencephalic locomotor region (DLR) (Manira et al., 1997; Ménard and Grillner, 2008), and is located ventral to the thalamus-a region analogous to the lateral hypothalamus in mammals (Ménard and Grillner, 2008). Unfortunately, like the MLR, the terminology used over the years has been confusing. Here we will use the historic SLR term but, where possible, we'll specify the anatomical region.

The SLR is necessary for goal-directed locomotion as bilateral ablation of the SLR abolishes spontaneous locomotion for several weeks following surgery (Shik and Orlovsky, 1976-original article in Russian: Sirota and Shik, 1973). Although, the SLR is connected to the MLR, the MLR is not necessary for SLRevoked locomotor behavior (Shik et al., 1969). It appears from these findings that the SLR serves as a parallel command system for locomotor control. What remains unclear is if the MRF 
is a necessary integration center to spinal cord to produce locomotion. In the lamprey, the DLR, an analog of the SLR in fish, projects to reticulospinal cells (Manira et al., 1997). However, in mammals, direct descending projections from the SLR and DLR to the spinal cord have been reported (Skagerberg and Lindvall, 1985; Sakurai, 2005; Stoyanova et al., 2010; Koblinger et al., 2014). Therefore, it is possible that an MRF-relay may not be necessary for all locomotor behaviors. A more likely scenario is that parallel pathways converge on spinal circuits to coordinate most behaviors.

Local infusion of glutamate agonists and GABA antagonists into the zona incerta (ZI) or the $\mathrm{LH}$ are sufficient to drive locomotor behaviors, suggesting that both inhibitory and excitatory afferents regulate SLR output (Di Scala et al., 1984; Milner and Mogenson, 1988; Sinnamon, 1993). The cell types of the ZI and LH have been well-characterized, and like other locomotor command centers are composed of heterogeneous cell types. These include fast-transmitting GABA, glutamatergic cells, and various peptidergic and neuromodulatory subtypes (review Mitrofanis, 2005; Stuber and Wise, 2016). Two modulatory systems that robustly drive locomotion are orexin (Valenstein et al., 1970; Valenstein, 1971; Ida et al., 1999; Thakkar et al., 2001; Sakurai, 2005; Siegel and Boehmer, 2006) and dopamine (Wagner et al., 1995; Kolmac and Mitrofanis, 1999).

The orexin cells in the brain originate mainly in the LH and activity of orexinergic cells is tightly coupled to the regulation of arousal, sleep, appetite, attention, and sensory modulation (Valenstein et al., 1970; Valenstein, 1971; Ida et al., 1999; Thakkar et al., 2001; Sakurai, 2005; Siegel and Boehmer, 2006). These cells have extensive projections throughout the brain including, but not limited to, the SNr, MLR, MRF, and spinal cord (Peyron et al., 1998; Sakurai, 2005; Stoyanova et al., 2010). Mice exhibit enhanced locomotor activity following intracerebroventricular administration of orexin (Hagan et al., 1999; Ida et al., 1999), and blocking orexin-1 receptors attenuates movement (Duxon et al., 2001). A recent study showed presence of orexin receptors on the reticulospinal MLR cells (Sherman et al., 2015). Moreover, focal injection of orexin into the MLR in decerebrate cats either reduced the intensity to evoke locomotion or elicited locomotion without stimulation, whereas an injection of orexin in either PPTg or SNr increased the intensity required to induce muscle atonia (Takakusaki et al., 2005). Recent work has reported that orexin cells may drive locomotor activity by increasing the activity of glutamic acid decarboxylase (GAD65)_expressing inhibitory neurons located in the LH. This population of inhibitory cells was found to be able to drive locomotor behavior when activated, and suppress locomotion when inhibited. These GAD65-expressing cells send projections to ZI, raphe magnus as well as superior colliculus and periaqueductal gray (Kosse et al., 2017; see section Interactions between Appetitive, Defensive, and Exploratory Behavior); however, the underlying circuitry responsible for orexinergic locomotor control requires further characterization.

The A13 and A11 dopaminergic nuclei are in the ZI and the rostral portion of the posterior hypothalamus, respectively. The contribution of the A11 to locomotor control is well characterized in zebrafish and is known as the diencephalospinal dopamine system (DDS; Tay et al., 2011; Lambert et al., 2012). The most recent work on the DDS demonstrates that these cells are rhythmically active during swimming and are both sufficient and necessary for swimming episodes (Jay et al., 2015). Currently, little is known about the locomotor functions of the A13 and A11 in mammals. However, the A11 projects to the spinal cord (Commissiong and Sedgwick, 1975; Skagerberg and Lindvall, 1985; Holstege et al., 1996; Koblinger et al., 2014; review Sharples et al., 2014) and has known roles in pain modulation (Charbit et al., 2009) and motor control (Ondo et al., 2000; Clemens et al., 2006; Qu et al., 2007). It has also been shown that dopamine modulates mammalian spinal CPG networks (Barrière et al., 2004; Humphreys and Whelan, 2012; Sharples et al., 2015; Picton et al., 2017; Sharples, 2017; Sharples and Whelan, 2017). These data support a possibility for a descending dopamine system in mammalian locomotor control. Nonetheless, the role of A11 and A13 cell populations in locomotor behaviors remains to be tested.

\section{FACTORS MEDIATING DECISION MAKING AND MOTOR SELECTION TO APPROACH OR TO AVOID}

So far, we have discussed locomotor regions by illustrating the nuclei and cell types involved in each pathway. These regions must interact with other brain areas to produce behaviorally relevant locomotion. Broadly speaking, there are two basic forms of locomotor responses observed in vertebrate species-approach or avoid-and a balance between these is necessary for survival (Glickman and Schiff, 1967). Here we will describe how internal (affective state, cognitive, reward, motivation, homeostatic, etc.) and external (sensory) cues are integrated to decide on approach or aversion (Figure 2A). We will describe the functional role of different types of locomotion based on their behavioral correlates, with emphasis on: (1) the role of the superior colliculus (SC) in deciding the appropriate locomotor response based on external sensory cues; (2) key limbic structures mediating locomotor responses based on internal cognitive and affective information; and (3) subsequent motor selection via the basal ganglia circuitry.

\section{EXTERNAL SENSORY CUES CAN FACILITATE APPROPRIATE MOTOR SELECTION}

External sensory cues are broadly classified as olfactory, visual, auditory, and tactile stimuli. When animals encounter such cues they must react appropriately to meet survival needs (Figure 2B).

The SC is an integral player in triggering appropriate locomotor responses based on novel visual stimuli in the environment. The superficial layers of the SC make use of retinotopic information relayed via the lateral geniculate nucleus of the thalamus (Nagata and Hayashi, 1984; Born and Schmidt, 2008) and primary visual cortex to orient the eyes, head, and body movement toward objects of interest (reviews Sparks, 1986; Grillner et al., 2008; Gandhi and Katnani, 2011). This permits the SC to trigger approach or avoidance responses based on visuospatial input. The location of visual information 


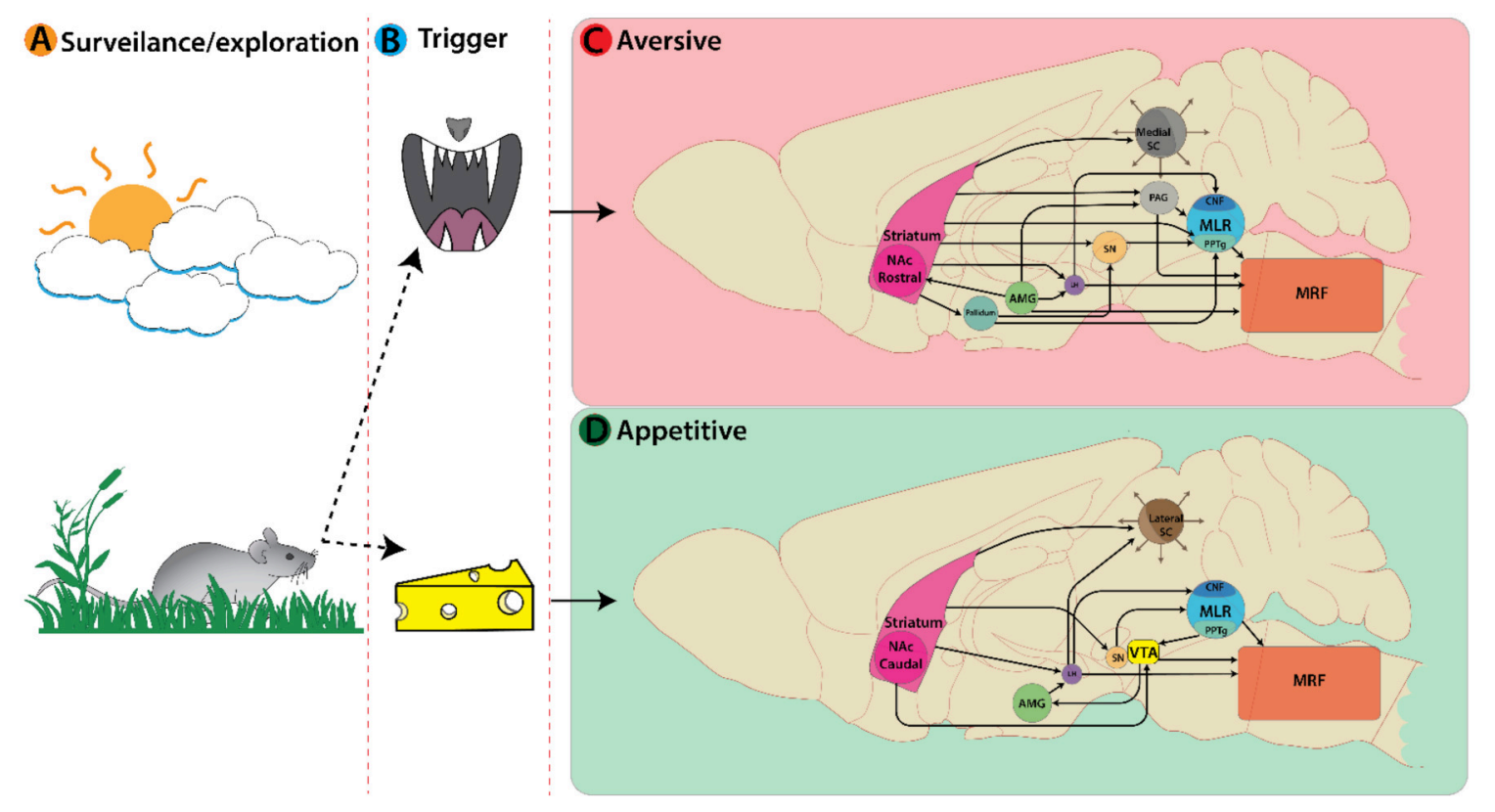

FIGURE 2 | Active nuclei in the mouse brain following a decision or trigger from a surveillance state. (A) Representation of an animal's decision process during a surveillance state. In this example a mouse encounters an aversive trigger (B top, predatory threat) activating nuclei associated with avoidance behaviors (C). Main nuclei active here are: Striatum, Amygdala, Superior colliculi, etc. On the bottom (B) the mouse encounters an appetitive trigger of food/cheese activating nuclei associated with approach behaviors (D).

within the visual field is key for identifying visual cues as food or a threat. Presenting an approaching visual stimulus in the upper visual field can evoke defensive responses such as escape and freezing in mice (Yilmaz and Meister, 2013). In rodents, predatory visual input is in the upper visual field and mapped in the medial SC (Figure 2C), whereas appetitive stimuli are detected in the lower visual field and mapped in the lateral SC (Comoli et al., 2012; Figure 2D). This functional organization is reflected by increased c-Fos protein expression (sign of recent neural activity) in the lateral SC following a hunting session for roaches on the floor (Favaro et al., 2011). In addition, unilateral electrical stimulation of lateral SC elicits contralateral orienting and approach-like responses, while stimulation of medial SC induces ipsilateral cringe-like defensive movement that develops into locomotion, running, and jumping with increasing stimulation intensity (Sahibzada et al., 1986). Such orienting responses involve contralateral MRF pathways, whereas movement away from the stimulus is mediated exclusively by an ipsilateral MRF pathways originating from the ventral and lateral SC (Sparks, 1986).

The SC projects ipsilaterally to the $\mathrm{CnF}$ and contralaterally to PPTg (Dean et al., 1989) with a major projection onto GABAergic MLR cells (Roseberry et al., 2016). The progression of locomotion elicited by stimulation of the medial SC is like that observed following stimulation at the MLR (Shik et al., 1969; Roseberry et al., 2016). One possibility is that this projection is inhibitory in nature, allowing for locomotion to occur via disinhibition of the MLR. Alternatively, if this circuit is glutamatergic, activation of GABAergic MLR neurons could suppress glutamatergic MLR output, producing motor arrest (see section Reflexive Startle Response Driven by Sudden External Sensory Stimuli).

\section{DECISIONS TO APPROACH OR AVOID ARE GUIDED BY INTERNALIZED CONTEXTUAL INFORMATION}

Generally, animals approach rewarding stimuli and avoid aversive stimuli. Aside from the positive and negative values associated with external stimuli, the coordination of approach- or aversive-like behaviors depend on the animal's internal affective and motivational states (Loewenstein et al., 2015). In early studies, Denny-Brown (1962) showed that bilateral lesions of the striatum caused animals to follow anything that moved. Since then the limbic system is understood to contribute to context-specific locomotion that drive decisions to approach or avoid.

Within the limbic system, the nucleus accumbens (NAc) of ventral striatum is an important limbic-motor interface underlying reward and motivation states (Mogenson et al., 1980; Roitman et al., 2005; Carlezon and Thomas, 2009; Levita et al., 2009; Humphries and Prescott, 2010; Richard and Berridge, 2011; McCutcheon et al., 2012; Salgado and Kaplitt, 2015). For example, amphetamine injected in the NAc results in hyperlocomotion demonstrating the key role of dopamine in both locomotion and reward. The NAc is divided into two subregions: 
the shell and the core. Traditionally, the shell of the NAc orchestrates the response to unconditioned, innate reward and indeed lesions of the shell produce hypolocomotion (Ito et al., 2004; Aragona et al., 2008; Ito and Hayen, 2011). On the other hand, the core mediates approach behaviors associated with Pavlovian reward-associated cues (Parkinson et al., 2000; Ito et al., 2004; Stefanik et al., 2013, 2016; Hamel et al., 2017). The NAc has diverse outputs that enable recruitment of locomotor circuits. The NAc recruits locomotor circuitry via projections to: globus pallidus (GP), substantia nigra pars compacta $(\mathrm{SNc})$, $\mathrm{SNr}, \mathrm{LH}$, ventral tegmental area (VTA), periaqueductal gray (PAG), PPTg, and ventral pallidum (VP) (Mogenson et al., 1983; review Nicola, 2007). It may be noted here that in some of these experiments PPTg also included overlapping brain regions including the $\mathrm{CnF}$. Together these outputs explain the strong locomotory effect of stimulation of the NAc [sections Locomotor Response in Anticipation of Reward and Defensive Locomotor Responses (Escape and Freeze) Associated with Aversive Cues].

The amygdala is implicated in decisions regarding approach and avoidance locomotor behaviors (Petrovich, 2011). Learned food cues are relayed to the LH from the basolateral amygdala complex (BLA) to facilitate feeding, and aversive cues can suppress feeding by direct and indirect projections from the central nucleus of the amygdala (CeA) to LH (Petrovich et al., 1996; Petrovich, 2011). Differential modulation by the CeA and BLA onto striatal projection neurons is known and thus can bias approach and avoid behavior selection (Wall et al., 2013). Discrete nuclei within the amygdala have direct and indirect projections to the PAG, which are involved in defensive locomotion (Gross and Canteras, 2012). Although, the amygdala is involved in both approach and avoidance, its role in driving the corresponding locomotor response to associated triggers requires interactions with various brain regions. The role of the amygdala in both appetitive and aversive locomotor behavior will be revisited separately in the following sections (sections from Motivation to Approach: Execution of Forward Locomotion and Reflexive Startle Response Driven by Sudden External Sensory Stimuli).

\section{MOTOR SELECTION DERIVED FROM THE DECISION TO APPROACH OR AVOID}

Both external and internal cues interact with basal ganglia (BG) circuits for precise execution and selection of appropriate locomotor behavior. One widely accepted hypothesis is that the direct dopamine pathway facilitates reward-oriented motor behavior (reviews Everitt and Robbins, 2013; Kim and Hikosaka, 2015; Grillner and Robertson, 2016; Averbeck and Costa, 2017) while the indirect pathway suppresses unrewarded movements. Hence, these two pathways may regulate most associative learning and reward-oriented motor actions (Frank, 2006; Kravitz et al., 2010; Hong and Hikosaka, 2011). The two pathways originate from GABAergic striatal projection neurons that are known as the direct and indirect pathway medium spiny neurons, dMSNs, and iMSNs, respectively (review Utter and Basso, 2008).
The dMSNs which express dopamine D1 receptors are excited by dopamine and project directly to the output nuclei of the basal ganglia, the SNr and GPi. Tonically active GABAergic projection neurons comprise these output nuclei and are responsible for tonic inhibition of the thalamus, SC, and PPTg. Thus, inhibition of GPi/SNr neurons by GABAergic dMSNs leads to disinhibition of brainstem motor centers and allow movement initiation. In contrast, iMSNs express dopamine D2 receptors and are inhibited by dopamine. These send GABAergic projections to the globus pallidus external (GPe) which in turn projects inhibitory output to the GPi. Sequentially, the GPe sends inhibitory output to excitatory STh that targets the SNr. Therefore, the net effect of the indirect pathway is an enhancement of inhibitory input from GPi and $\mathrm{SNr}$ to the descending motor centers. The GPi/SNr projects to the PPTg providing tonic inhibition affecting locomotor behavior. The anatomical tracing studies provide evidence for SNc projections to the PPN in rat (Beckstead et al., 1979; Semba and Fibiger, 1992; Steininger et al., 1992; Ichinohe et al., 2000) and in cat (Edley and Graybiel, 1983). The presence of such descending input was also supported by recordings of short latency antidromic activation of SNc neurons following PPN stimulation in rat (Scarnati et al., 1984, 1987). This is important as it suggests that dopamine has exclusive projections to brainstem nuclei distinct from the BG circuitry (Ryczko and Dubuc, 2013; Ryczko et al., 2016), which adds an extra degree of monoaminergic control over movement initiation.

\section{PRIMARY APPETITIVE LOCOMOTOR SYSTEM: APPROACH-LIKE RESPONSES TO REWARDING \& APPETITIVE CUES}

Internalized contextual information such as reward and motivation combine to form approach-like behaviors across species. For example, place preference and self-stimulation paradigms often require association with rewarding cues, such as food to facilitate subsequent approach responses toward stimuli. Here we will examine work focused on how locomotion toward a rewarding stimulus is achieved. We will describe the functional connectivity between the limbic circuitry and descending locomotor centers, relevant for mediating forward locomotion in the context of appetitive behaviors (Figure 3).

\section{FROM MOTIVATION TO APPROACH: EXECUTION OF FORWARD LOCOMOTION}

The motivation to approach a stimulus in the environment stems from associations between the stimulus and its value as a physiological need or reward. Limbic structures such as the amygdala are key in mediating an approach locomotor response toward a rewarding stimulus such as food. As mentioned in section Decisions to Approach or Avoid are Guided by Internalized Contextual Information, the amygdala (BLA) directly projects to the LH which is a key hub for appetitive behaviors. The $\mathrm{LH}$ is an 


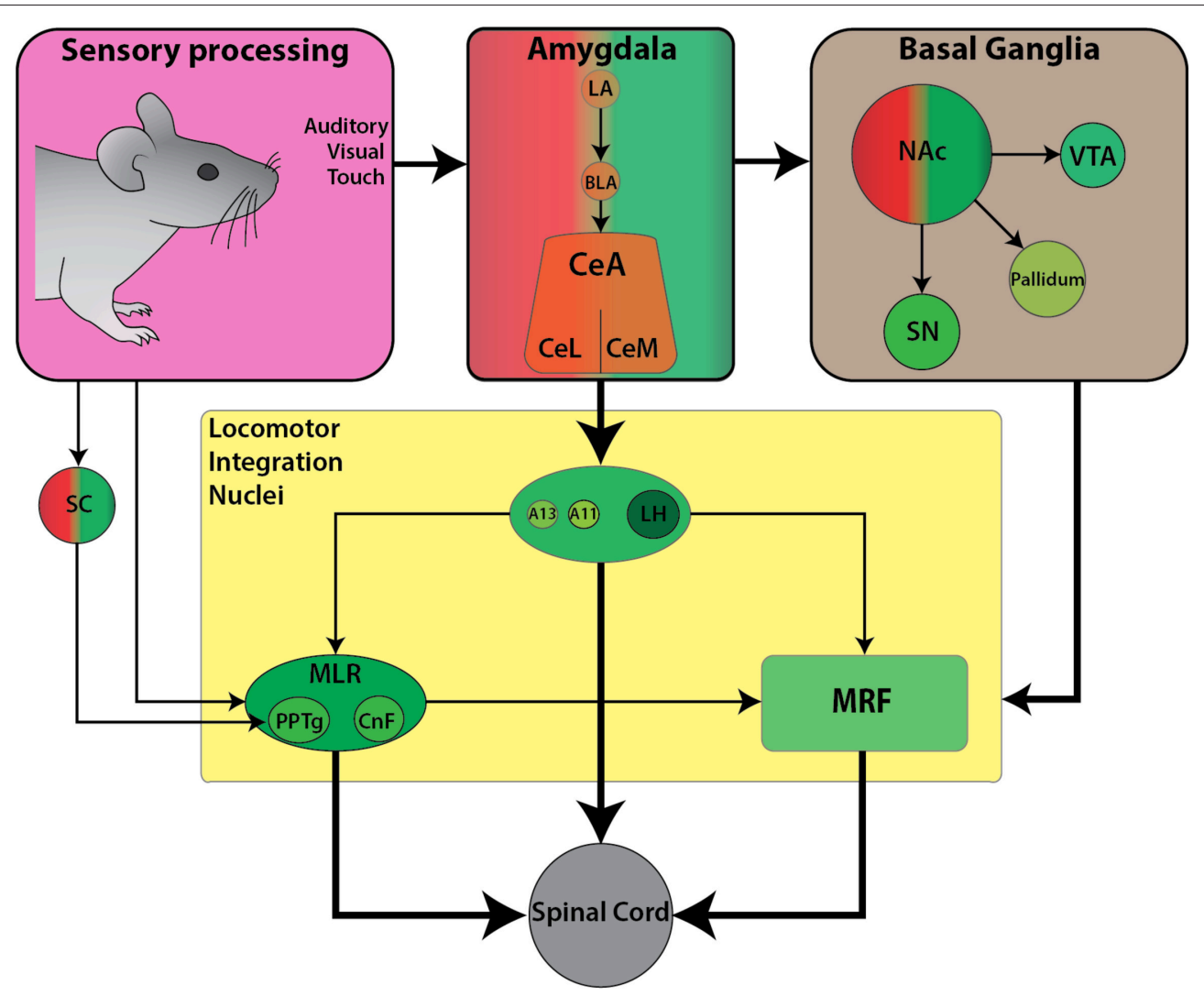

FIGURE 3 | Schematic diagram of the currently known descending connectivity of appetitive (approach) locomotor control. (Complementary to Figure 2D. Some connections omitted for lack of data or complexity of connectivity). Weighted arrows represent complex connectivity between regions described in further detail in text. Ascending connectivity has been omitted for clarity.

excellent candidate for investigating how reward-related information integrates with descending locomotor centers to facilitate forward locomotion toward reward-associated stimuli.

The LH is a large structure and has multiple functions. In the locomotor field, the initial descriptions of the $\mathrm{LH}$ were studied in the context of appetitive locomotor control (Sinnamon, 1993). However, most recent work has been directed toward the role of the $\mathrm{LH}$ in modulating homeostatic demands. Electrical stimulation of the LH elicits diverse responses beyond locomotion, such as feeding, drinking, gnawing and predatory attack that often vary from animal to animal but are linked to the current external stimuli (Coons et al., 1965; Roberts and Carey, 1965; Mogenson and Stevenson, 1967; review Stuber and Wise, 2016). Several LH cell populations have been shown to play a key role in feeding and appetite regulation including orexin, GABAergic, and glutamatergic cells. Projections onto the $\mathrm{LH}$ are predictably diverse and include olfactory and pyriform cortex, NAc, dorsal striatum, GP, ZI, perifornical region, most hypothalamic areas including magnocellular and medial preoptic, supraoptic, paraventricular and periventricular nuclei, posterior hypothalamus, arcuate and mammillary nuclei, bed nucleus of stria terminalis, ventral thalamic nuclei, VTA, SN,
MRF, PAG, locus coeruleus, and parabrachial region (Barone et al., 1981).

The LH orexinergic transmission plays a key role in mediating locomotor responses via SN and brainstem locomotor regions (section The Diencephalon: A Hub for Goal-Directed Locomotion) and are active during feeding behavior (de Lecea et al., 1998; Sakurai et al., 1998), reward and arousal (Peyron et al., 1998; Baldo et al., 2003; Harris et al., 2005; Swanson et al., 2005; Aston-Jones et al., 2010). Indeed, the orexinergic neuronal population shows the highest level of spiking activity when animals are moving toward a food source. Orexinergic neurons are not the only LH neurons involved in locomotion; recently GABAergic LH cells have been reported to contribute to modulate locomotor activity. Chemogenetic silencing of LH GABAergic cells depresses voluntary locomotion, while stimulation leads to hyper-locomotion (Kosse et al., 2017). Anterograde tracing of these GABAergic cells uncovered substantial projections onto the ZI. The downstream projections are unknown. These ZI cells could also be modulated by orexin since photostimulation of orexinergic cells rapidly recruits GABAergic $\mathrm{LH}$ cells, and spiking of these GABAergic $\mathrm{LH}$ cells precedes spontaneous running bouts (Kosse et al., 2017). 


\section{LOCOMOTOR RESPONSE IN ANTICIPATION OF REWARD}

While motivation contributes to an animal's approach behavior toward rewarding stimuli (Mogenson et al., 1980), anticipation of reward can also drive forward locomotion. Such anticipatory reward signals are integrated to locomotor centers via corticolimbic structures including the cortex, striatum and pallidum, which have descending projections to the locomotor regions (Swanson, 2000).

As well as participating in motor selection (section Motor Selection Derived from the Decision to Approach or Avoid), dopamine circuits including mesolimbic, mesocortical, and nigrostriatal pathways govern reward-related behaviors. Dopamine release within the NAc is an important determinant of reward processing. Furthermore, NAc is known to have reciprocal projections to dopaminergic neurons in VTA and the SN which projects to the dorsal striatum (Haber et al., 2000; Ikemoto, 2007). The dorsal striatum and its dopaminergic inputs serve key roles in the regulation of locomotor control (Faure et al., 2005; Belin and Everitt, 2008; Palmiter, 2008). Striatal pathway projections are differentially modulated by dopamine, and are either excitatory via the direct pathway (D1 receptor) or inhibitory via the indirect pathway (D2 receptor) (Surmeier et al., 2007). The locomotor modulation observed within BG circuitry could occur via glutamatergic and cholinergic MLR neurons that mediate initiation and acceleration of locomotion while GABAergic populations could facilitate deceleration, respectively (Roseberry et al., 2016). Dopaminergic fibers have been reported around cholinergic cells in MLR of lamprey (Ryczko et al., 2013), salamander (Ryczko et al., 2016), rat (Ryczko et al., 2016), monkeys (Rolland et al., 2009), and human (Ryczko et al., 2016) indicating that the innervation of the MLR is conserved in vertebrates (Ryczko and Dubuc, 2017). In lamprey and salamander, the origin of this dopaminergic innervation to cholinergic cells in MLR was found to be a diencephalic dopaminergic region termed as posterior tuberculum which sends ascending projections to the striatum and is considered homologous to mammalian $\mathrm{SNc}$ and/or VTA (Yamamoto and Vernier, 2011; Wullimann, 2014; Ryczko et al., 2016; Ryczko and Dubuc, 2017). While only a few dopamine neurons sent collaterals to the striatum and the MLR in lampreys and salamanders, numerous SNc dopamine neurons have both ascending and descending collaterals in rats (Ryczko et al., 2016). The number of ascending dopaminergic collaterals may be related to evolutionary expansion of the basal ganglia (Grillner and Robertson, 2016; Ryczko and Dubuc, 2017). These findings suggest that the role of dopaminergic activity in reward-related behavior is bidirectional and could occur in anticipation of obtaining a reward.

Following a similar theme, neurons within the PPTg are important for modulating speed and gait during locomotion (section The Mesencephalic Locomotor Region: An Integrative Hub for Locomotor Speed and Gait), but also respond in anticipation of reward signals. PPTg neurons respond phasically to auditory and visual sensory stimuli that predict reward with a shorter latency $(5-10 \mathrm{~ms})$ than dopaminergic VTA/SNc cells
(Pan and Hyland, 2005). Furthermore, Norton et al. (2011) examined PPTg neural activity as rats solved a spatial working memory task that involved retrieving rewards of different magnitudes from known locations. Interestingly, they reported separate populations of PPTg neurons independently code for reward or movement. Thus, the reward anticipatory response within PPTg is part of a feedforward mechanism to trigger a fast locomotor response triggered by a reward-associated cue. In support of this idea, photoactivation of cholinergic PPTg terminals at $\mathrm{SNc}$ has been shown to increase locomotion (Xiao et al., 2016). Electrical stimulation of PPTg induces a burst firing of midbrain dopaminergic neurons (Lokwan et al., 1999; Floresco et al., 2003) with concomitant release of dopamine in striatum (Chapman et al., 1996; Miller and Blaha, 2004). This suggests that the PPTg may facilitate feedforward and feedback loops with $\mathrm{SNc}$ via reciprocal projections. Calcium transients within dopaminergic terminals in dorsal striatum precede $(100-150 \mathrm{~ms})$ bouts of locomotion independent of reward expectation (Howe and Dombeck, 2016). Photoactivation of these dopaminergic axons leads to initiation of locomotion bouts. Thus, rapid subsecond phasic signaling contributes to locomotion bout initiation associated with ongoing accelerations. Since glutamatergic MLR cells can facilitate acceleration (Roseberry et al., 2016), the role of these populations in potentiating locomotion in anticipation of reward is of interest.

\section{PRIMARY DEFENSIVE LOCOMOTOR SYSTEM: AVOIDANCE RESPONSES TO AVERSIVE ASSOCIATED CUES}

Locomotion is a critical element in the primary defensive system since it serves to increase the distance away from threatening or painful stimuli (Sinnamon, 1993). In general, aversive behaviors are characterized by three types of responses: (1) a reflexive startle response, (2) escape behavior to flee from an aversive stimulus, and (3) a freezing response. Of these three defensive responses, the circuitry for startle response has been best described. On the other hand, escape and freezing responses have often been used as behavioral outcomes in pain and fear related studies, but the associated locomotor components have received less attention (reviews Klemm, 2001; Roseberry and Kreitzer, 2017; Figure 4).

\section{REFLEXIVE STARTLE RESPONSE DRIVEN BY SUDDEN EXTERNAL SENSORY STIMULI}

The mammalian startle response is characterized by fast twitch of facial and body muscles as well as an arrest of ongoing movement in response to a sudden and intense sensory stimulus (Koch, 1999). It protects the animal from predation by preparing for a flight or fight response, or by freezing so the animal can't be easily seen (Landis and Hunt, 1939). A startle response can be elicited by different sensory modalities which act via separate pathways. These include: (1) trigeminal for sudden tactile stimuli, (2) auditory 


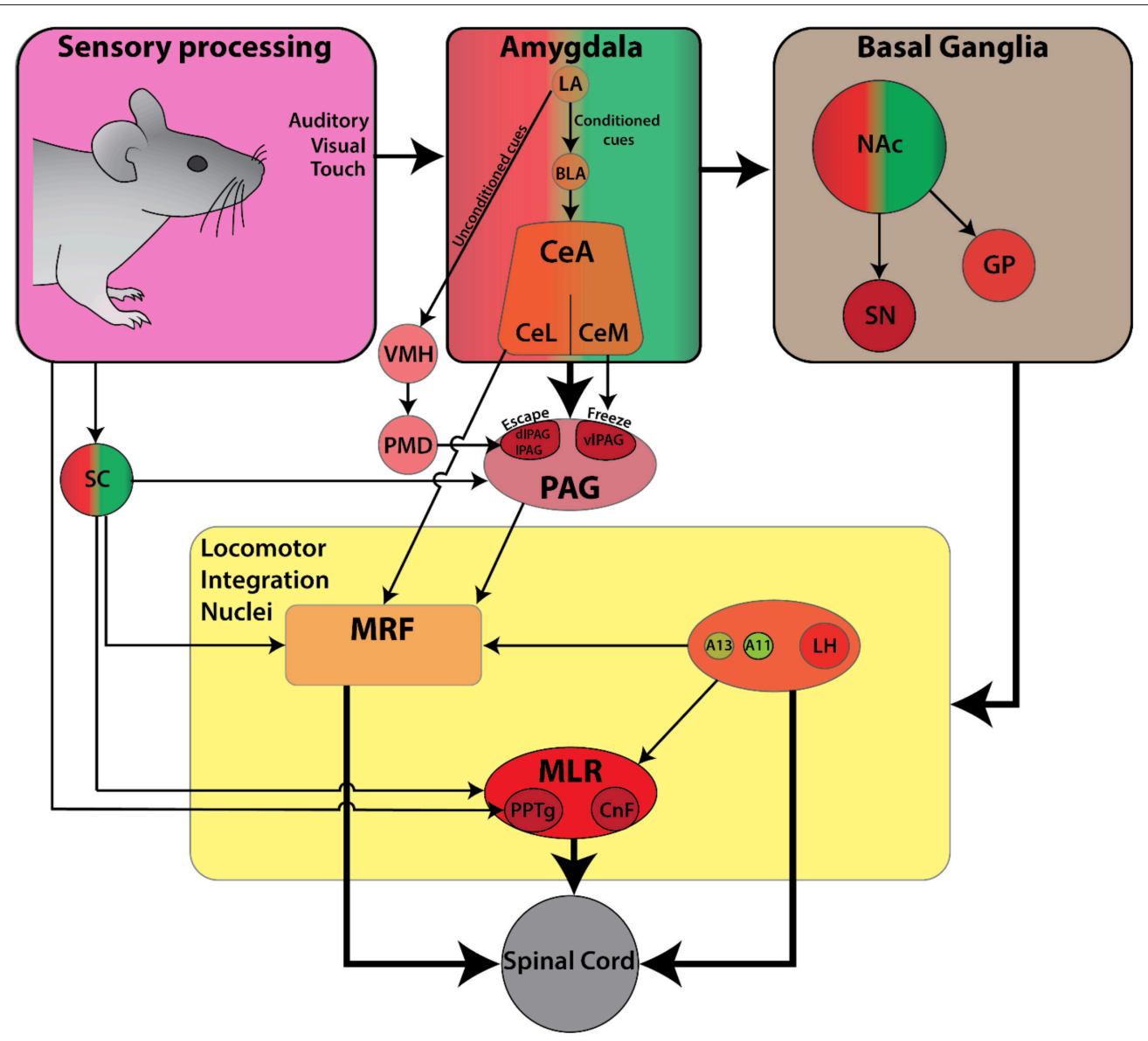

FIGURE 4 | Schematic diagram of the currently known descending connectivity of defensive (avoidance) locomotor control. (Complementary to Figure 2C. Some connections omitted for lack of data or complexity of connectivity). Ascending connectivity has been omitted for clarity.

for sudden acoustic stimuli, and (3) vestibular for sudden head movements. Though these startle pathways originate from different second-order afferents (nucleus $\mathrm{V}$ for tactile, cochlear root nucleus for auditory, and vestibular nucleus for balance), they converge onto giant neurons in the $\mathrm{PnC}$ projecting directly to motoneurons and interneurons of the spinal cord (reviews Koch, 1999; Yeomans et al., 2002). Less well understood is the light-induced startle response characterized by temporary locomotor arrest following brief flashes of light (Liang et al., 2015). This phenomenon can be partly driven by input to the SC from layer 5 of the primary visual cortex (V1 L5). Photoactivation of V1 L5 neurons projecting to SC directly triggers locomotor arrest in running mice (Liang et al., 2015). Inactivating the SC with muscimol reduces the arrest behavior by $76 \%$, whereas silencing V1 by optical activation of parvalbuminpositive inhibitory neurons reduces arrest by 33\% (Liang et al., 2015). Overall, these startle pathways are fine-tuned to detect specific triggers from the environment during the default exploration state of the animal, allowing an animal to quickly transition into a defensive state (Yeomans and Frankland, 1995).

\section{DEFENSIVE LOCOMOTOR RESPONSES (ESCAPE AND FREEZE) ASSOCIATED WITH AVERSIVE CUES}

In comparison to the startle response, which is reflexive in nature, the choice between escaping a stimulus and freezing is highly dependent on contextual cues. Behavioral outcomes that measure fear and pain such as conditioned place preference/aversion and dynamic weight bearing analysis rely on quantification of locomotor behavior. The descending control of locomotor circuits in response to aversive stimuli has not been fully explored. Nonetheless, aversive responses rely heavily on locomotor circuit interactions between the amygdala and PAG (LeDoux, 2012; Koutsikou et al., 2015, 2017).

Aversive stimuli can be thought of as either unconditioned and innate, or learned and associated with pain and fear. The association between the unconditioned stimulus and the conditioned stimulus required may involve memory processing related to fear. This is mediated in part by both the CeA and BLA of the amygdala (LeDoux, 2000; Medina et al., 2002; Wilensky et al., 2006; Ciocchi et al., 2010; Duvarci et al., 2011; 
Li et al., 2013; Han et al., 2015; Sato et al., 2015). The CeA is an important neural substrate for the expression of the freeze response (Davis and Whalen, 2001; Phelps and LeDoux, 2005). It projects to the hypothalamus, dorsal and ventral striatum, PAG, and MRF, and could also modulate cognition in a broader sense, via its outputs to ascending monoaminergic and cholinergic systems such as: noradrenergic LC, dopaminergic SNc and VTA, serotonergic raphe, and the cholinergic nucleus basalis (Davis and Whalen, 2001; Sara, 2009). Recent cell-type-specific viral tracing studies have also revealed a strong projection from the CeA to glutamatergic MLR neurons, which can initiate locomotion from rest when activated (Roseberry et al., 2016). Similarly, chemical or electrical stimulation of CeA can elicit freezing or fleeing behavior (Brandão et al., 1999, 2015; Vianna et al., 2001; Muthuraju et al., 2016). Thus, the CeA is important for orchestrating defensive freeze and escape responses (Sah et al., 2003; Oka et al., 2008).

The PAG also plays a central role in regulating defensive locomotor behaviors. Bandler was the first to show the PAG's direct role in defensive reactions in cats by pharmacological activation with microinjections of glutamate (Bandler, 1982) and excitatory amino acids (Bandler and Carrive, 1988). Subsequent studies identified five subregions that can be differentiated based on anatomy, physiology, and behavioral outcomes when activated (Carrive, 1993). The dorsolateral/lateral (dl/l) and ventrolateral (vl) columns of the PAG appear to be the most relevant in the context of defensive locomotor behaviors. Activation of the IPAG can elicit a variety of responses such as: strong hindlimb movements for flight reaction, reactive immobility accompanied by heightened responsiveness to surrounding stimuli, backward locomotion, and forward escape locomotion with occasional jumps (Bandler and Depaulis, 1988; Depaulis et al., 1989, 1992; Carrive, 1993). Meanwhile, activation of the vlPAG can induce hyporeactive immobility characterized by reduced spontaneous activity and/or responsiveness to surrounding stimuli (Bandler and Depaulis, 1988; Depaulis et al., 1992; Carrive, 1993). In line with this, electrolytic lesions of vlPAG in rats decrease freezing induced by unconditioned and conditioned stimuli, whereas lesions of dlPAG enhanced freezing (Fanselow et al., 1995; De Oca et al., 1998). Photoactivation of glutamatergic cells of the dorsal PAG (dPAG) can evoke both freeze and escape behavior in a gradual manner via firing rate and temporal coding mechanism (Chen et al., 2015). Increasing either frequency or intensity of photoactivation progressed defensive phenotype from freeze to escape and then to jump. Given the lack of a clear boundary between observed phenotypes, it is possible that these cells may perform this function through differing neurotransmitter release and/or its afferent and efferent connections.

Sensory cues that trigger aversive behaviors are either unconditioned or conditioned, and are processed through different pathways. Unconditioned odor cues are conveyed via the medial amygdala, whereas auditory and visual cues are conveyed via the accessory basal amygdala. These signals are further processed through the circuitry of the ventromedial hypothalamus ( $\mathrm{VMH})$-premammillary nucleus of the hypothalamus (PMH) and the dPAG. On the other hand, conditioned cues are processed via the LA and intraamygdala connections onto $\mathrm{CeA}$, and then project onto vlPAG from medial CeA (CeM) (Motta et al., 2009). The CeA also projects directly onto PnC (Davis and Whalen, 2001) where Chx10 stop neurons could be found (Bouvier et al., 2015) and glutamatergic MLR neurons which are associated with acceleration of ongoing movement (Roseberry et al., 2016). Therefore, defensive responses may be mediated through these projections as well. Furthermore, glutamatergic cells within PAG innervate the GiA, GiV, and LPGi (Tovote et al., 2016). Most work has focused primarily on fear induced freezing; however, the neural circuitry of PAG-mediated defensive locomotor control remains undefined. Considering this, Tovote et al. (2016) selectively manipulated inhibitory projections from the CeA to local inhibitory interneurons within the vlPAG. Glutamatergic neurons of the vlPAG are under local inhibition, and upon disinhibition by the $\mathrm{CeA}$, they induce freezing via $\mathrm{GiA}, \mathrm{GiV}$, and LPGi targets. In contrast to activation of glutamatergic vlPAG neurons, photostimulation of glutamatergic dl/lPAG neurons evoke bouts of escape locomotor behavior intermingled with short freezing periods (Tovote et al., 2016). It seems that the PAG could play an important role in translating locomotor behaviors related to freezing or escape and may interact with locomotor command centers. A few studies suggest that an interaction between PAG and locomotor command centers (e.g., $\mathrm{CnF}$ ) may be relevant for locomotor behaviors in freezing and/or escape (Ferreira-Netto et al., 2007). Connectivity between PAG and Chx10 neurons within caudal $\mathrm{PnC}$ and rostral $\mathrm{Gi}$ which can evoke stop has not yet been explored. With these multiple possible points of integration between the pain, limbic, and motor systems that have been found through tracing techniques, we can begin to create testable models of functional circuitry within specific contexts that modulate locomotion.

\section{INTERACTIONS BETWEEN APPETITIVE, DEFENSIVE, AND EXPLORATORY BEHAVIOR}

Appetitive, defensive and exploratory locomotor behavior are all necessary for survival. This is reflected at the neural systems level, where processes for these behaviors are closely intertwined along with circuits involved in maintenance of food and resources, defense, fluid balance, thermoregulation, and reproduction (Saper, 2006). Eating must often co-exist with the threat of predation for many species. The risks need to be weighed with the rewards and clearly, they are weighed differently in satiated compared to hungry animals. In the above sections, we have provided examples of nuclei that contribute to this complex predation calculus such as SC, NAc, and amygdala.

Since the locomotor responses are driven by the animal's interaction with the environment, there are multiple overlapping cognitive or associative and emotional processing structures modulating locomotor responses. Nevertheless, differential signaling processes for various contexts can facilitate approach while suppressing avoidance responses and vice versa. For 
example, GABA cells in the LH are excited by orexin and activity of these cells drives locomotion (section The Diencephalon: A Hub for Goal-Directed Locomotion). These inhibitory cells project to the SC and the PAG; both of which drive aversive locomotor behaviors. These inhibitory circuits are strong candidates for the suppression of aversive locomotor behaviors in situations where motivation to seek food is high.

In summary, innervation onto NAc could disinhibit the MLR via VP and the SNr to initiate, modulate or terminate locomotion. In addition, BLA and CeA send efferents to dMSNs preferentially (Roseberry et al., 2016) and the LH area (Petrovich et al., 1996; Petrovich, 2011), which could facilitate approach locomotion for cues associated with food and reward, or mediate suppression of appetitive behavior during defensive response and unrewarded movement, respectively. For example, in a behavioral conflict between aversion and reward, cholinergic and glutamatergic PPTg projections onto the dopaminergic VTA neurons may mediate a bias toward reward-oriented locomotion. Furthermore, PPTg projections to dopaminergic SNc neurons may facilitate suppression of unrewarded movements via the indirect pathway, or reinforce reward oriented motor action via direct pathway (Frank, 2006; Kravitz et al., 2010; Hong and Hikosaka, 2011). In addition, A11 and A13 (DLR) could provide a parallel dopaminergic modulation to mediate a balance between approach and avoidance behaviors.

\section{FUTURE DIRECTIONS}

This review has examined how locomotion is integrated into contextual demands. Recent advances in functional connectomics will enable us to decipher the circuits that underlie different approach and avoid motor behaviors. Specifically, optogenetics and chemogenetics coupled with viral-vector based approaches provide the tool kits necessary to advance our understanding. These methods can overcome limitations of electrical stimulation, and lesion approaches. That said direct comparisons with electrical stimulation remain useful since translational approaches using deep brain stimulation rely on this technology. In some cases, electrical stimulation may be advantageous since it's lack of selectivity may be required to adequately activate a network. Electrical stimulation will recruit more neurons due to failures in transfection. While optogenetics and chemogenetics are an excellent choice for understanding the connectome we need to carefully evaluate if these are the tool of choice for clinical use.

It is sobering to consider that establishing the connectome from an anatomical point of view is only half the story; the dynamic recruitment of multiple parallel pathways also needs to be considered. No matter which nuclei one focuses on there are multiple projections to other members within the overall circuit. We need to consider sampling key areas of the circuit simultaneously when designing studies so that we can begin to understand the dynamic recruitment of several centers during approach and avoidance tasks. These centers will include the PPTg, CnF, and MRF since they form key integrative centers in the brain. Depending on the type of study recordings need to be captured from the striatum, hypothalamic nuclei, and the LC.

\section{CHALLENGES FACED IN DRIVING CONTEXTUAL BEHAVIORAL RESPONSE}

Meanwhile, as more sophisticated technologies and experimental tools became readily available, thus enabling the study of underlying mechanisms and circuitries associated with motor functions with much higher precision, there are several caveats. It is important to consider that the study of motor behaviors using experimental animal models generally require extensive training or conditioning, which rely on memory and learning processes. The impact of this training on the motor behavior being tested needs to be understood.

Learning and memory formation were initially thought to be driven by dynamic changes in synaptic strengths, which can be experimentally induced by high frequency stimulation (Bliss and Lomo, 1973). A few key regions of the brain were implicated, including the hippocampus, the neocortex, cerebellar, and brainstem nuclei (Medina et al., 2002). This is known as the synaptic plasticity and memory hypothesis, within this there are assumptions that synaptic inputs converge, or there are specific "relay centres" for information processing. This hypothesis has been reappraised because the mechanisms underlying the initial encoding and subsequent learning are likely to be different (Medina et al., 2002). This can be demonstrated by the observations that: (1) habituation occurs over relatively short periods of time for certain behaviors (e.g., forced swim, open field induced anxiety); and (2) neuronal plasticity often persists even when the conditioned behavior has fully extinguished (Hansel et al., 2001). The key point here is that whilst neuronal plasticity in specific regions contributes to the initiation of behavior, the maintenance may involve activity of other neuronal populations or pathways.

Similarly, the extinction of behaviors (e.g., fear extinction), indicate that learning is a state-dependent process. It was established that the amygdala, a brain region important for the regulation of emotion, receives input from the hippocampus and provides "context" (i.e., based on the animal's affective states) during conditioning (Phelps and LeDoux, 2005). In line with this review, modulation of locomotor behaviors is also contextdependent and are driven by the animal's need and/or adaptation to the ever-changing environments. At present, many studies investigating changes in cellular mechanisms or functional circuitry associated with motor behaviors are relatively shortterm compared to behavior studies from other fields, such as sensory and cognitive neuroscience. Future studies must consider appropriate experiment paradigms to account for the changes in behaviors over time, and that there may be multiple changes at both cellular and systems levels in context-driven motor learning.

\section{CONCLUSION}

To navigate through the environment, animals need to make onthe-fly adjustments to gait. Consider a baseball player running 
to catch a ball. The person will need to be motivated to run quickly to catch the ball, and this motivation may be higher at the World Series compared to a regular training day. Catching the ball requires visual input which is integrated through the dorsal stream to the motor cortex, which is then relayed back to diencephalic circuits including the BG and hypothalamic circuits. Modifications to gait need to be accomplished to execute accelerations, jumps, and slides. This is presumably integrated at the level of the MRF and MLR and integrated into ongoing activity within rhythm centers of the spinal cord. We are at a critical juncture in our understanding of how emotional and contextual cues affect locomotor performance. Many tools exist to tease apart circuit function in awake behaving animals and show how they affect downstream brainstem and spinal cord function. This of course dramatically increases the complexity of experiments directed at understanding motor control, but it will serve to highlight the interplay between regions of the brain involved in movement decisions that evolved to maximize survival of the organism.

\section{REFERENCES}

Alam, M., Schwabe, K., and Krauss, J. K. (2011). The pedunculopontine nucleus area: critical evaluation of interspecies differences relevant for its use as a target for deep brain stimulation. Brain 134, 11-23. doi: 10.1093/brain/ awq322

Alam, M., Schwabe, K., and Krauss, J. (2013). Reply: the cuneiform nucleus may be involved in the regulation of skeletal muscle tone by motor pathway: a virally mediated trans-synaptic tracing study in surgically sympathectomized mice. Brain 136, e252. doi: 10.1093/brain/awt125

Aragona, B. J., Cleaveland, N. A., Stuber, G. D., Day, J. J., Carelli, R. M., Wightman, R. M. (2008). Preferential enhancement of dopamine transmission within the nucleus accumbens shell by cocaine is attributable to a direct increase in phasic dopamine release events. J. Neurosci. 28, 8821-8831. doi: 10.1523/JNEUROSCI.2225-08.2008

Armstrong, D. M. (1986). Supraspinal contributions to the initiation and control of locomotion in the cat. Prog. Neurobiol. 26, 273-361. doi: 10.1016/0301-0082(86)90021-3

Aston-Jones, G., Smith, R., Sartor, G., Moorman, D., Massi, L., TahsiliFahadan, P., et al. (2010). Lateral hypothalamic orexin/hypocretin neurons: a role in reward-seeking and addiction. Brain Res. 1314, 74-90. doi: 10.1016/j.brainres.2009.09.106

Averbeck, B. B., and Costa, V. D. (2017). Motivational neural circuits underlying reinforcement learning. Nat. Neurosci. 20, 505-512. doi: 10.1038/ nn. 4506

Baldo, B. A., Daniel, R. A., Berridge, C. W., and Kelley, A. E. (2003). Overlapping distributions of orexin/hypocretin- and dopamine- $\beta$-hydroxylase immunoreactive fibers in rat brain regions mediating arousal, motivation, and stress. J. Comp. Neurol. 464, 220-237. doi: 10.1002/cne.10783

Bandler, R. (1982). Induction of "page" following microinjections of glutamate into midbrain but not hypothalamus of cats. Neurosci. Lett. 30, 183-188. doi: 10.1016/0304-3940(82)90294-4

Bandler, R., and Carrive, P. (1988). Integrated defence reaction elicited by excitatory amino acid microinjection in the midbrain periaqueductal grey region of the unrestrained cat. Brain Res. 439, 95-106. doi: 10.1016/0006-8993(88)91465-5

Bandler, R., and Depaulis, A. (1988). Elicitation of intraspecific defence reactions in the rat from midbrain periaqueductal grey by microinjection of kainic acid, without neurotoxic effects. Neurosci. Lett. 88, 291-296. doi: 10.1016/0304-3940(88)90226-1

\section{AUTHOR CONTRIBUTIONS}

All authors (LK, SS, SAS, KM, CC, and PW) contributed to the conception, drafting, and critical revision of the review.

\section{FUNDING}

We would like to acknowledge funding awarded to PW from the Canadian Institute for Health Research (CIHR MOP130528; PJT-148682), Natural Sciences and Engineering Research Council of Canada (NSERC RGPIN/356153-2013), Wings for Life (WFL-CA011/15), the Hotchkiss Brain Institute (HBI) and Faculty for Veterinary Medicine. LK was supported by the Alberta Parkinson's Society and the Cumming School of Medicine, KM was supported by the Branch Out Foundation and $\mathrm{HBI}$ and SAS supported by Alberta Innovates and HBI.

\section{ACKNOWLEDGMENTS}

We would like to acknowledge support from members of the Whelan Lab.

Barone, F. C., Wayner, M. J., Scharoun, S. L., Guevara-Aguilar, R., and AguilarBaturoni, H. U. (1981). Afferent connections to the lateral hypothalamus: a horseradish peroxidase study in the rat. Brain Res. Bull. 7, 75-88. doi: 10.1016/0361-9230(81)90101-5

Barrière, G., Mellen, N., and Cazalets, J. (2004). Neuromodulation of the locomotor network by dopamine in the isolated spinal cord of newborn rat. Eur. J. Neurosci. 19, 1325-1335. doi: 10.1111/j.1460-9568.2004.03210.x

Beckstead, R. M., Domesick, V. B., and Nauta, W. J. (1979). Efferent connections of the substantia nigra and ventral tegmental area in the rat. Brain Res. 175, 191-217. doi: 10.1016/0006-8993(79)91001-1

Beitz, A. J. (1982a). The sites of origin brain stem neurotensin and serotonin projections to the rodent nucleus raphe magnus. J. Neurosc. 2, 829-842.

Beitz, A. J. (1982b). The nuclei of origin of brain stem enkephalin and substance pprojections to the rodent nucleus raphe magnus. Neuroscience 7, 2753-2768. doi: 10.1016/0306-4522(82)90098-7

Belin, D., and Everitt, B. (2008). Cocaine seeking habits depend upon dopaminedependent serial connectivity linking the ventral with the dorsal Striatum. Neuron 57, 432-441. doi: 10.1016/j.neuron.2007.12.019

Bliss, T. V., and Lomo, T. (1973). Long-lasting potentiation of synaptic transmission in the dentate area of the anaesthetized rabbit following stimulation of the perforant path. J. Physiol. 232, 331-356. doi: 10.1113/jphysiol.1973.sp010273

Boothby, K. M., and Roberts, A. (1992). The stopping response of Xenopus laevis embryos: behaviour, development and physiology. J. Comp. Physiol. A 170, 171-180. doi: 10.1007/BF00196899

Born, G., and Schmidt, M. (2008). A reciprocal connection between the ventral lateral geniculate nucleus and the pretectal nuclear complex and the superior colliculus: an in vitro characterization in the rat. Vis. Neurosci. 25, 39-51. doi: 10.1017/S0952523808080048

Bouvier, J., Caggiano, V., Leiras, R., Caldeira, V., Bellardita, C., Balueva, K., et al. (2015). Descending command neurons in the brainstem that halt locomotion. Cell 163, 1191-1203. doi: 10.1016/j.cell.2015.10.074

Brandão, M. L., Anseloni, V. Z., Pandóssio, J. E., Araújo, J. E., and Castilho, V. M. (1999). Neurochemical mechanisms of the defensive behavior in the dorsal midbrain. Neurosci. Biobehav. Rev. 23, 863-875. doi: 10.1016/S0149-7634(99)00038-X

Brandão, M., de Oliveira, A., Muthuraju, S., Colombo, A., Saito, V., and Talbot, T. (2015). Dual role of dopamine $\mathrm{D}_{2}$-like receptors in the mediation of conditioned and unconditioned fear. FEBS Lett. 589, 3433-3437. doi: 10.1016/j.febslet.2015.02.036 
Bretzner, F., and Brownstone, R. (2013). Lhx3-Chx10 reticulospinal neurons in locomotor circuits. J. Neurosci. 33, 14681-14692. doi: 10.1523/JNEUROSCI.5231-12.2013

Brustein, E., and Rossignol, S. (1998). Recovery of locomotion after ventral and ventrolateral spinal lesions in the cat. I. Deficits and adaptive mechanisms. J. Neurophysiol. 80, 1245-1267.

Carlezon, W. A., and Thomas, M. J. (2009). Biological substrates of reward and aversion: a nucleus accumbens activity hypothesis. Neuropharmacology 56, 122-132. doi: 10.1016/j.neuropharm.2008.06.075

Carrive, P. (1993). The periaqueductal gray and defensive behavior: functional representation and neuronal organization. Behav. Brain Res. 58, 27-47. doi: 10.1016/0166-4328(93)90088-8

Castiglioi, A. J., Gallaway, M. C., and Coulter, J. D. (1978). Spinal projections from the midbrain in monkey. J. Comp. Neurol. 178, 329-345. doi: 10.1002/cne.901780208

Chapman, C., Yeomans, J., Blaha, C., and Blackburn, J. (1996). Increased striatal dopamine efflux follows scopolamine administered systemically or to the tegmental pedunculopontine nucleus. Neuroscience 76, 177-186. doi: 10.1016/S0306-4522(96)00358-2

Charbit, A. R., Akerman, S., Holland, P. R., and Goadsby, P. J. (2009). Neurons of the dopaminergic/calcitonin gene-related peptide A1l cell group modulate neuronal firing in the trigeminocervical complex: an electrophysiological and immunohistochemical study. J. Neurosci. 29, 12532-12541. doi: 10.1523/JNEUROSCI.2887-09.2009

Chen, S., Zhou, H., Guo, S., Zhang, J., Qu, Y., Feng, Z., et al. (2015). Optogenetics based rat-robot control: optical stimulation encodes "stop" and "escape" commands. Ann. Biomed. Eng. 43, 1851-1864. doi: 10.1007/s10439-014-1235-x

Ciocchi, S., Herry, C., Grenier, F., Wolff, S. B., Letzkus, J., Vlachos, I., Ehrlich, I., et al. (2010). Encoding of conditioned fear in central amygdala inhibitory circuits. Nature 468, 277-282. doi: 10.1038/nature09559

Clemens, S., Rye, D., and Hochman, S. (2006). Restless legs syndrome: revisiting the dopamine hypothesis from the spinal cord perspective. Neurology 67, 125-130. doi: 10.1212/01.wnl.0000223316.53428.c9

Clements, J. R., and Grant, S. (1990). Glutamate-like immunoreactivity in neurons of the laterodorsal tegmental and pedunculopontine nuclei in the rat. Neurosci. Lett. 120, 70-73. doi: 10.1016/0304-3940(90)90170-E

Commissiong, J. W., and Sedgwick, E. M. (1975). Letter: dopamine and noradrenaline in human spinal cord. Lancet 1, 347. doi: 10.1016/S0140-6736(75)91269-6

Comoli, E., Favaro, P., Vautrelle, N., Leriche, M., Overton, P. G., and Redgrave, P. (2012). Segregated anatomical input to sub-regions of the rodent superior colliculus associated with approach and defense. Front. Neuroanat. 6:9. doi: $10.3389 /$ fnana.2012.00009

Coons, E. E., Levak, M., and Miller, N. E. (1965). Lateral hypothalamus: learning of food-seeking response motivated by electrical stimulation. Science 150, 1320-1321. doi: 10.1126/science.150.3701.1320

Coulter, J. D., Bowker, R. M., Wise, S. P., Murray, E. A., Castiglioni, A. J., and Westlund, K. N. (1979). Cortical, tectal and medullary descending pathways to the cervical spinal cord. Prog. Brain Res. 50, 263-274. doi: 10.1016/S0079-6123(08)60827-4

Davis, M., and Whalen, P. (2001). The amygdala: vigilance and emotion. Mol. Psychiatry 6, 13-34. doi: 10.1038/sj.mp. 4000812

de Lecea, L., Kilduff, T. S., Peyron, C., Gao, X.-B., Foye, P. E., Danielson, P. E., et al. (1998). The hypocretins: hypothalamus-specific peptides with neuroexcitatory activity. Proc. Natl. Acad. Sci. U.S.A. 95, 322-327. doi: 10.1073/pnas. 95.1.322

De Oca, B. M., DeCola, J. P., Maren, S., and Fanselow, M. S. (1998). Distinct regions of the periaqueductal gray are involved in the acquisition and expression of defensive responses. J. Neurosci. 18, 3426-3432.

Dean, P., Redgrave, P., and Westby, G. W. M. (1989). Event or emergency? Two response systems in the mammalian superior colliculus. Trends Neurosci. 12, 137-147. doi: 10.1016/0166-2236(89)90052-0

Denny-Brown, D. (1962). The Basal Ganglia and Their Relation to Disorder of Movement. New York, NY: Oxford University Press Inc.

Depaulis, A., Bandler, R., and Vergnes, M. (1989). Characterization of pretentorial periaqueductal gray matter neurons mediating intraspecific defensive behaviors in the rat by microinjections of kainic acid. Brain Res. 486, 121-132. doi: 10.1016/0006-8993(89)91284-5
Depaulis, A., Keay, K. A., and Bandler, R. (1992). Longitudinal neuronal organization of defensive reactions in the midbrain periaqueductal gray region of the rat. Exp. Brain Res. 90, 307-318. doi: 10.1007/BF00227243

Di Scala, G., Schmitt, P., and Karli, P. (1984). Flight induced by infusion of bicuculline methiodide into periventricular structures. Brain Res. 309, 205-209. doi: 10.1016/0006-8993(84)90585-7

Drew, T., Dubuc, R., and Rossignol, S. (1986). Discharge patterns of reticulospinal and other reticular neurons in chronic, unrestrained cats walking on a treadmill. J. Neurophysiol. 55, 375-401.

Drew, T., Prentice, S., and Schepens, B. (2004). Cortical and brainstem control of locomotion. Prog. Brain Res. 143, 251-261. doi: 10.1016/S0079-6123(03)43025-2

Duvarci, S., Popa, D., and Paré, D. (2011). Central amygdala activity during fear conditioning. J. Neurosci. 31, 289-294. doi: 10.1523/JNEUROSCI.4985-10.2011

Duxon, M., Stretton, J., Starr, K., Jones, D., Holland, V., Riley, G., et al. (2001). Evidence that orexin-A-evoked grooming in the rat is mediated by orexin-1 $\left(\mathrm{OX}_{1}\right)$ receptors, with downstream $5-\mathrm{HT}_{2 \mathrm{C}}$ receptor involvement. Psychopharmacology 153, 203-209. doi: 10.1007/s002130000550

Ectors, L., Brookens, N. L., and Gerard, R. W. (1938). Autonomic and motor localization in the hypothalamus. Arch. Neurol. Psychiatry 39, 789-798. doi: 10.1001/archneurpsyc.1938.02270040145009

Edley, S. M., and Graybiel, A. M. (1983). The afferent and efferent connections of the feline nucleus tegmenti pedunculopontinus, pars compacta. J. Comp. Neurol. 217, 187-215. doi: 10.1002/cne.902170207

Edwards, D. H., Heitler, W. J., and Krasne, F. B. (1999). Fifty years of a command neuron: the neurobiology of escape behavior in the crayfish. Trends Neurosci. 22, 153-161. doi: 10.1016/S0166-2236(98)01340-X

Esch, T., and Kristan, W. (2002). Decision-making in the leech nervous system. Integr. Comp. Biol. 42, 716-724. doi: 10.1093/icb/42.4.716

Esposito, M. S., Capelli, P., and Arber, S. (2014). Brainstem nucleus MdV mediates skilled forelimb motor tasks. Nature 508, 351-356. doi: 10.1038/nature13023

Everitt, B. J., and Robbins, T. W. (2013). From the ventral to the dorsal striatum: devolving views of their roles in drug addiction. Neurosci. Biobehav. Rev. 37 , 1946-1954. doi: 10.1016/j.neubiorev.2013.02.010

Fanselow, M., Decola, J., Oca, B., and Landeira-Fernandez, J. (1995). Ventral and dorsolateral regions of the midbrain periaqueductal gray (PAG) control different stages of defensive behavior: dorsolateral PAG lesions enhance the defensive freezing produced by massed and immediate shock. Aggress. Behav. 21, 63-77. doi: 10.1002/1098-2337(1995)21:1<63::AID-AB2480210109>3.0. $\mathrm{CO} ; 2-\mathrm{F}$

Faure, A., Haberland, U., Condé, F., and Massioui, N. (2005). Lesion to the nigrostriatal dopamine system disrupts stimulus-response habit formation. J. Neurosci. 25, 2771-2780. doi: 10.1523/JNEUROSCI.3894-04.2005

Favaro, P. D. N., Gouvêa, T. S., de Oliveira, S. R., Vautrelle, N., Redgrave, P., and Comoli, E. (2011). The influence of vibrissal somatosensory processing in rat superior colliculus on prey capture. Neuroscience 176, 318-327. doi: 10.1016/j.neuroscience.2010.12.009

Ferraye, M. U., Debû, B., Fraix, V., Goetz, L., Ardouin, C., Yelnik, J., et al. (2010). Effects of pedunculopontine nucleus area stimulation on gait disorders in Parkinson's disease. Brain 133, 205-214. doi: 10.1093/brain/awp229

Ferreira-Netto, C., Borelli, K. G., and Brandão, M. L. (2007). Distinct Fos expression in the brain following freezing behavior elicited by stimulation with NMDA of the ventral or dorsal inferior colliculus. Exp. Neurol. 204, 693-704. doi: 10.1016/j.expneurol.2006.12.023

Fetcho, J. R., Higashijima, S., and McLean, D. L. (2008). Zebrafish and motor control over the last decade. Brain Res. Rev. 57, 86-93. doi: 10.1016/j.brainresrev.2007.06.018

Floresco, S. B., West, A. R., Ash, B., Moore, H., and Grace, A. A. (2003). Afferent modulation of dopamine neuron firing differentially regulates tonic and phasic dopamine transmission. Nat. Neurosci. 6, 968-973. doi: 10.1038/nn1103

Ford, B., Holmes, C. J., Mainville, L., and Jones, B. E. (1995). GABAergic neurons in the rat pontomesencephalic tegmentum: codistribution with cholinergic and other tegmental neurons projecting to the posterior lateral hypothalamus. J. Comp. Neurol. 363, 177-196. doi: 10.1002/cne.9036 30203

Fortin, M., and Parent, A. (1999). Calretinin-immunoreactive neurons in primate pedunculopontine and laterodorsal tegmental nuclei. Neuroscience 88 , 535-547. doi: 10.1016/S0306-4522(98)00214-0 
Frank, M., J. (2006). Dynamic dopamine modulation in the basal ganglia: a neurocomputational account of cognitive deficits in medicated and nonmedicated Parkinsonism. J. Cogn. Neurosci. 17, 51-72. doi: $10.1162 / 0898929052880093$

Gandhi, N. J., and Katnani, H. A. (2011). Motor functions of the superior colliculus. Annu. Rev. Neurosci. 34, 205-231. doi: 10.1146/annurev-neuro-061010-113728

Garcia-Rill, E., and Skinner, R. D. (1987a). The mesencephalic locomotor region. I. Activation of a medullary projection site. Brain Res. 411, 1-12. doi: 10.1016/0006-8993(87)90675-5

Garcia-Rill, E., and Skinner, R. D. (1987b). The mesencephalic locomotor region. II. Projections to reticulospinal neurons. Brain Res. 411, 13-20. doi: 10.1016/0006-8993(87)90676-7

Gillette, R., Kovac, M. P., and Davis, W. J. (1978). Command neurons in Pleurobranchaea receive synaptic feedback from the motor network they excite. Science 199, 798-801. doi: 10.1126/science.622571

Glickman, S. E., and Schiff, B. B. (1967). A biological theory of reinforcement. Psychol. Rev. 74, 81-109. doi: 10.1037/h0024290

Grillner, S., and Robertson, B. (2016). The basal ganglia over 500 million years. Curr. Biol. 26, R1088-R1100. doi: 10.1016/j.cub.2016.06.041

Grillner, S., Hongo, T., and Lund, S. (1968). The origin of descending fibres monosynaptically activating spinoreticular neurones. Brain Res. 10, 259-262. doi: 10.1016/0006-8993(68)90130-3

Grillner, S., Wallén, P., Saitoh, K., Kozlov, A., and Robertson, B. (2008). Neural bases of goal-directed locomotion in vertebrates-An overview. Brain Res. Rev. 57, 2-12. doi: 10.1016/j.brainresrev.2007.06.027

Gross, C. T., and Canteras, N. S. (2012). The many paths to fear. Nat. Rev. Neurosci. 13, 651-658. doi: 10.1038/nrn3301

Grossen, N. E., and Kelley, M. J. (1972). Species-specific behavior and acquisition of avoidance behavior in rats. J. Comp. Physiol. Psychol. 81, 307. doi: $10.1037 / \mathrm{h} 0033536$

Grossman, R. (1958). Effects of stimulation of non-specific thalamic system on locomotor movements in cat. J. Neurophysiol. 21, 85-93.

Haber, S. N., Fudge, J. L., and McFarland, N. R. (2000). Striatonigrostriatal pathways in primates form an ascending spiral from the shell to the dorsolateral striatum. J. Neurosci. 20, 2369-2382. Available online at: http://www.jneurosci. org/content/20/6/2369

Hagan, J. J., Leslie, R. A., and Patel, S. (1999). Orexin A activates locus coeruleus cell firing and increases arousal in the rat. Proc. Natl. Acad. Sci. U.S.A. 96, 10911-10916. doi: 10.1073/pnas.96.19.10911

Hägglund, M., Borgius, L., Dougherty, K. J., and Kiehn, O. (2010). Activation of groups of excitatory neurons in the mammalian spinal cord or hindbrain evokes locomotion. Nat. Neurosci. 13, 246-252. doi: 10.1038/nn.2482

Hamel, L., Thangarasa, T., Samadi, O., and Ito, R. (2017). Caudal nucleus accumbens core is critical in the regulation of cue-elicited approach-avoidance decisions. eNeuro 4:ENEURO.0330-16.2017. doi: 10.1523/ENEURO.0330-16.2017

Han, S., Soleiman, M. T., Soden, M. E., Zweifel, L. S., and Palmiter, R. D. (2015). Elucidating an affective pain circuit that creates a threat memory. Cell 162, 363-374. doi: 10.1016/j.cell.2015.05.057

Hansel, C. E., Linden, D. J., and D'Angelo, E. (2001). Beyond parallel fiber LTD: the diversity of synaptic and non-synaptic plasticity in the cerebellum. Nat. Neurosci. 4, 467-475. doi: 10.1038/87419

Harris, G., Wimmer, M., and Aston-Jones, G. (2005). A role for lateral hypothalamic orexin neurons in reward seeking. Nature 437, 556-559. doi: 10.1038 /nature 04071

Heise, C., and Mitrofanis, J. (2006). Fos immunoreactivity in some locomotor neural centres of 6OHDA-lesioned rats. Anat. Embryol. 211, 659-671. doi: 10.1007/s00429-006-0130-0

Hirsch, E. C., Graybiel, A. M., Duyckaerts, C., and Javoy-Agid, F. (1987). Neuronal loss in the pedunculopontine tegmental nucleus in Parkinson disease and in progressive supranuclear palsy. Proc. Natl. Acad. Sci. U.S.A. 84, 5976-5980. doi: 10.1073/pnas.84.16.5976

Holstege, J. C. (1991). Ultrastructural evidence for GABAergic brain stem projections to spinal motoneurons in the rat. J. Neurosci. 11, 159-167.

Holstege, J. C., Van Dijken, H., Buijs, R. M., Goedknegt, H., Gosens, T., and Bongers, C. M. (1996). Distribution of dopamine immunoreactivity in the rat, cat, and monkey spinal cord. J. Comp. Neurol. 376, 631-652. doi: 10.1002/(SICI)1096-9861(19961223)376:4<631::AID-CNE10>3.0.CO;2-P
Hong, S., and Hikosaka, O. (2011). Dopamine-mediated learning and switching in cortico-striatal circuit explain behavioral changes in reinforcement learning. Front. Behav. Neurosci. 5:15. doi: 10.3389/fnbeh.2011.00015

Howe, M. W., and Dombeck, D. A. (2016). Rapid signalling in distinct dopaminergic axons during locomotion and reward. Nature 535, 505-510. doi: 10.1038/nature18942

Humphreys, J. M., and Whelan, P. J. (2012). Dopamine exerts activationdependent modulation of spinal locomotor circuits in the neonatal mouse. $J$. Neurophysiol. 108, 3370-3381. doi: 10.1152/jn.00482.2012

Humphries, M. D., and Prescott, T. J. (2010). The ventral basal ganglia, a selection mechanism at the crossroads of space, strategy, and reward. Prog. Neurobiol. 90, 385-417. doi: 10.1016/j.pneurobio.2009.11.003

Ichinohe, N., Teng, B., and Kitai, S. T. (2000). Morphological study of the tegmental pedunculopontine nucleus, substantia nigra and subthalamic nucleus, and their interconnections in rat organotypic culture. Anat. Embryol. 201, 435-453. doi: 10.1007/s004290050331

Ida, T., Nakahara, K., Katayama, T., and Murakami, N. (1999). Effect of lateral cerebroventricular injection of the appetite-stimulating neuropeptide, orexin and neuropeptide $Y$, on the various behavioral activities of rats. Brain Res. 821 , 526-529. doi: 10.1016/S0006-8993(99)01131-2

Ikemoto, S. (2007). Dopamine reward circuitry: two projection systems from the ventral midbrain to the nucleus accumbens-olfactory tubercle complex. Brain Res. Rev. 56, 27-78. doi: 10.1016/j.brainresrev.2007.05.004

Inglis, W. L., Dunbar, J. S., and Winn, P. (1994). Outflow from the nucleus accumbens to the pedunculopontine tegmental nucleus: a dissociation between locomotor activity and the acquisition of responding for conditioned reinforcement stimulated by d-amphetamine. Neuroscience 62, 51-64. doi: 10.1016/0306-4522(94)90314-X

Ito, R., and Hayen, A. (2011). Opposing roles of nucleus accumbens core and shell dopamine in the modulation of limbic information processing. J. Neurosci. 31, 6001-6007. doi: 10.1523/JNEUROSCI.6588-10.2011

Ito, R., Robbins, T. W., and Everitt, B. (2004). Differential control over cocaineseeking behavior by nucleus accumbens core and shell. Nat. Neurosci. 7 , 389-397. doi: 10.1038/nn1217

Jankowska, E., Hammar, I., Slawinska, U., Maleszak, K., and Edgley, S. A. (2003). Neuronal basis of crossed actions from the reticular formation on feline hindlimb motoneurons. J. Neurosci. 23, 1867-1878. Available online at: http:// www.jneurosci.org/content/23/5/1867.long

Jay, M., De Faveri, F., and McDearmid, J. (2015). Firing dynamics and modulatory actions of supraspinal dopaminergic neurons during zebrafish locomotor behavior. Curr. Biol. 25, 435-444. doi: 10.1016/j.cub.2014.12.033

Jellinger, K. (1988). The pedunculopontine nucleus in Parkinson's disease, progressive supranuclear palsy and Alzheimer's disease. J. Neurol. Neurosurg. Psychiatry 51, 540-543. doi: 10.1136/jnnp.51.4.540

Jordan, L. M. (1998). Initiation of locomotion in mammals. Ann. N.Y. Acad. Sci. 860, 83-93. doi: 10.1111/j.1749-6632.1998.tb09040.x

Jordan, L. M., Liu, J., Hedlund, P. B., Akay, T., and Pearson, K. G. (2008). Descending command systems for the initiation of locomotion in mammals. Brain Res. Rev. 57, 183-191. doi: 10.1016/j.brainresrev.2007.07.019

Kaelber, W. W., and Smith, T. B. (1979). Projections of the zona incerta in the cat, with stimulation controls. Exp. Neurol. 63, 177-200. doi: 10.1016/0014-4886(79)90192-4

Kiehn, O. (2016). Decoding the organization of spinal circuits that control locomotion. Nat. Rev. Neurosci. 17, 224-238. doi: 10.1038/nrn.2016.9

Kim, H. F., and Hikosaka, O. (2015). Parallel basal ganglia circuits for voluntary and automatic behaviour to reach rewards. Brain 138, 1776-1800. doi: 10.1093/brain/awv134

Kimura, Y., Satou, C., Fujioka, S., Shoji, W., Umeda, K., Ishizuka, T., et al. (2013). Hindbrain V2a neurons in the excitation of spinal locomotor circuits during zebrafish swimming. Curr. Biol. 23, 843-849. doi: 10.1016/j.cub.2013. 03.066

Klemm, W. R. (2001). Behavioral arrest: in search of the neural control system. Prog. Neurobiol. 65, 453-471. doi: 10.1016/S0301-0082(01) 00016-8

Kneisley, L. W., Biber, M. P., and LaVail, J. H. (1978). A study of the origin of brainstem projections to monkey spinal cord using the retrograde transport method. Exp. Neurol. 60, 116-139. doi: 10.1016/0014-4886(78) 90172-3 
Koblinger, K., Füzesi, T., Ejdrygiewicz, J., Krajacic, A., Bains, J., and Whelan, P. (2014). Characterization of A11 neurons projecting to the spinal cord of mice. PLoS ONE 9:e109636. doi: 10.1371/journal.pone.0109636

Koch, M. (1999). The neurobiology of startle. Prog. Neurobiol. 59, 107-128. doi: 10.1016/S0301-0082(98)00098-7

Koch, M., Kungel, M., and Herbert, H. (1993). Cholinergic neurons in the pedunculopontine tegmental nucleus are involved in the mediation of prepulse inhibition of the acoustic startle response in the rat. Exp. Brain Res. 97, 71-82. doi: $10.1007 /$ BF00228818

Kolmac, C., and Mitrofanis, J. (1999). Distribution of various neurochemicals within the zona incerta: an immunocytochemical and histochemical study. Anat. Embryol. 199, 265-280. doi: 10.1007/s004290050227

Kosse, C., Schöne, C., Bracey, E., and Burdakov, D. (2017). Orexin-driven GAD65 network of the lateral hypothalamus sets physical activity in mice. Proc. Natl. Acad. Sci. U.S.A. 114, 4525-4530. doi: 10.1073/pnas.1619700114

Koutsikou, S., Apps, R., and Lumb, B. (2017). Top down control of spinal sensorimotor circuits essential for survival. J. Physiol. 595, 4151-4158. doi: 10.1113/JP273360

Koutsikou, S., Watson, T. C., Crook, J. J., Leith, J. L., Lawrenson, C. L., Apps, R., et al. (2015). The periaqueductal gray orchestrates sensory and motor circuits at multiple levels of the neuraxis. J. Neurosci. 35, 14132-14147. doi: 10.1523/JNEUROSCI.0261-15.2015

Kravitz, A., Freeze, B., Parker, P., Kay, K., Thwin, M., Deisseroth, K., et al. (2010). Regulation of parkinsonian motor behaviours by optogenetic control of basal ganglia circuitry. Nature 466, 622-626. doi: 10.1038/nature09159

Kroeger, D., Ferrari, L., Petit, G., Mahoney, C., Fuller, P., Arrigoni, E., et al. (2017). Cholinergic, glutamatergic, and GABAergic neurons of the pedunculopontine tegmental nucleus have distinct effects on sleep/wake behavior in mice. J. Neurosci. 37, 1352-1366. doi: 10.1523/JNEUROSCI.1405-16.2016

Krutki, P., Jankowska, E., and Edgley, S. A. (2003). Are crossed actions of reticulospinal and vestibulospinal neurons on feline motoneurons mediated by the same or separate commissural neurons? J. Neurosci. 23, 8041-8050.

Lambert, A. M., Bonkowsky, J. L., Masino, M. A. (2012). The conserved dopaminergic diencephalospinal tract mediates vertebrate locomotor development in zebrafish larvae. J. Neuroscience. 32, 13488-13500. doi: 10.1523/JNEUROSCI.1638-12.2012

Lamprea, M. R., Cardenas, F. P., Setem, J., and Morato, S. (2008). Thigmotactic responses in an open-field. Braz. J. Med. Biol. Res. 41, 135-140. doi: 10.1590/S0100-879X2008000200010

Landis, C., and Hunt, W. (1939). The Startle Pattern. Oxford: Farrar \& Rinehart.

Lavoie, B., and Parent, A. (1994). Pedunculopontine nucleus in the squirrel monkey: cholinergic and glutamatergic projections to the substantia nigra. J. Comp. Neurol. 344, 232-241. doi: 10.1002/cne.903440205

LeDoux, J. (2000). Emotion circuits in the brain. Annu. Rev. Neurosci. 23, 155-184. doi: 10.1146/annurev.neuro.23.1.155

LeDoux, J. (2012). Rethinking the emotional brain. Neuron 73, 653-676. doi: 10.1016/j.neuron.2012.02.004

Leppänen, P., Ravaja, N., and Ewalds-Kvist, S. B. M. (2006). Twenty-three generations of mice bidirectionally selected for open-field thigmotaxis: selection response and repeated exposure to the open field. Behav. Process. 72, 23-31. doi: 10.1016/j.beproc.2005.11.010

Levita, L., Hare, T. A., Voss, H., Glover, G., Ballon, D. J., and Casey, B. J. (2009). The bivalent side of the nucleus accumbens. Neuroimage 44, 1178-1187. doi: 10.1016/j.neuroimage.2008.09.039

Li, H., Penzo, M. A., Taniguchi, H., Kopec, C. D., Huang, Z. J., and Li, B. (2013). Experience-dependent modification of a central amygdala fear circuit. Nat. Neurosci. 16, 332-339. doi: 10.1038/nn.3322

Li, W.-C. C., Perrins, R., Walford, A., and Roberts, A. (2003). The neuronal targets for GABAergic reticulospinal inhibition that stops swimming in hatchling frog tadpoles. J. Comp. Physiol. A 189, 29-37. doi: 10.1007/s00359-0020372-0

Liang, F., Xiong, X., Zingg, B., Ji, X., Zhang, L., and Tao, H. (2015). Sensory cortical control of a visually induced arrest behavior via corticotectal projections. Neuron 86, 755-767. doi: 10.1016/j.neuron.2015.03.048

Liang, H., Paxinos, G., and Watson, C. (2011). Projections from the brain to the spinal cord in the mouse. Brain Struct. Funct. 215, 159-186. doi: $10.1007 /$ s00429-010-0281-x
Liang, H., Paxinos, G., and Watson, C. (2012). Spinal projections from the presumptive midbrain locomotor region in the mouse. Brain Struct. Funct. 217, 211-219. doi: 10.1007/s00429-011-0337-6

Liu, J., and Jordan, L. M. (2005). Stimulation of the parapyramidal region of the neonatal rat brain stem produces locomotor-like activity involving spinal 5-HT7 and 5-HT2A receptors. J. Neurophysiol. 94, 1392-1404. doi: $10.1152 /$ jn. 00136.2005

Loewenstein, G., O'donoghue, T., and Bhatia, S. (2015). Modeling the interplay between affect and deliberation. Decision 2, 55-81. doi: 10.1037/dec0000029

Lokwan, S. J., Overton, P. G., Berry, M. S., and Clark, D. (1999). Stimulation of the pedunculopontine tegmental nucleus in the rat produces burst firing in A9 dopaminergic neurons. Neuroscience 92, 245-254. doi: 10.1016/S0306-4522(98)00748-9

Magnuson, D., Schramm, M., and MacLean, J. (1995). Long-duration, frequency-dependent motor responses evoked by ventrolateral funiculus stimulation in the neonatal rat spinal cord. Neurosci. Lett. 192, 97-100. doi: 10.1016/0304-3940(95)99208-M

Manira, E., Pombal, M. A., and Grillner, S. (1997). Diencephalic projection to reticulospinal neurons involved in the initiation of locomotion in adult lampreys Lampetra fluviatilis. J. Comp. Neurol. 389, 603-616. doi: 10.1002/(SICI)1096-9861(19971229)389:4<603::AID-CNE5>3.0.CO;2-4

Masserman, J. H. (1938). Destruction of the hypothalamus in cats: effects of activity of the central nervous system and its reaction to sodium amytal. Arch. Neurol. Psychiatry 39, 1250-1271. doi: 10.1001/archneurpsyc.1938.02270060 140007

Matsuyama, K., Mori, F., Kuze, B., and Mori, S. (1999). Morphology of single pontine reticulospinal axons in the lumbar enlargement of the cat: a study using the anterograde tracer PHA-L. J. Comp. Neurol. 410, 413-430. doi: 10.1002/(SICI)1096-9861(19990802)410:3<413::AID-CNE5>3.0.CO;2-Q

McCutcheon, J., Ebner, S., Loriaux, A., and Roitman, M. (2012). Encoding of aversion by dopamine and the nucleus accumbens. Front. Neurosci. 6:137. doi: 10.3389/fnins.2012.00137

Medina, J., Repa, C., Mauk, M., and LeDoux, J. (2002). Parallels between cerebellum- and amygdala-dependent conditioning. Nat. Rev. Neurosci. 3, 122-131. doi: 10.1038/nrn728

Mel'nikova, Z. L. (1975). Locomotion of rats induced by stimulation of the mesencephalon. Bull. Moscow Univ. 30, 45-51.

Mel'nikova, Z. L. (1977). Study of the relationships between the "locomotor regions" of the subthalamus and midbrain in rats. Neirofiziol. Neurophysiol. 9, 275-280.

Ménard, A., and Grillner, S. (2008). Diencephalic locomotor region in the lamprey-Afferents and efferent control. J. Neurophysiol. 100, 1343-1353. doi: 10.1152/jn.01128.2007

Mena-Segovia, J., and Bolam, J. P. (2017). Rethinking the pedunculopontine nucleus: from cellular organization to function. Neuron 94, 7-18. doi: 10.1016/j.neuron.2017.02.027

Mena-Segovia, J., Micklem, B. R., Nair-Roberts, R. G., Ungless, M. A., and Bolam, J. P. (2009). GABAergic neuron distribution in the pedunculopontine nucleus defines functional subterritories. J. Comp. Neurol. 515, 397-408. doi: $10.1002 /$ cne. 22065

Mena-Segovia, J., Sims, H. M., Magill, P. J., and Bolam, J. P. (2008). Cholinergic brainstem neurons modulate cortical gamma activity during slow oscillations. J. Physiol. 586, 2947-2960. doi: 10.1113/jphysiol.2008.153874

Miller, A., and Blaha, C. (2004). Nigrostriatal dopamine release modulated by mesopontine muscarinic receptors. Neuroreport 15:1805. doi: 10.1097/01.wnr.0000135692.81613.85

Milner, K., and Mogenson, G. (1988). Electrical and chemical activation of the mesencephalic and subthalamic locomotor regions in freely moving rats. Brain Res. 452, 273-285. doi: 10.1016/0006-8993(88)90031-5

Mitrofanis, J. (2005). Some certainty for the "zone of uncertainty"? Exploring the function of the zona incerta. Neuroscience 130, 1-15. doi: 10.1016/j.neuroscience.2004.08.017

Mogenson, G. J., and Stevenson, J. A. F. (1967). Drinking induced by electrical stimulation of the lateral hypothalamus. Exp. Neurol. 17, 119-127. doi: 10.1016/0014-4886(67)90139-2

Mogenson, G. J., Jones, D., and Yim, C. (1980). From motivation to action: functional interface between the limbic system and the motor system. Prog. Neurobiol. 14, 69-97. doi: 10.1016/0301-0082(80)90018-0 
Mogenson, G. J., Swanson, L. W., and Wu, M. (1983). Neural projections from nucleus accumbens to globus pallidus, substantia innominata, and lateral preoptic-lateral hypothalamic area: an anatomical and electrophysiological investigation in the rat. J. Neurosci. 3, 189-202.

Mori, S., Sakamoto, T., Ohta, Y., Takakusaki, K., and Matsuyama, K. (1989). Site-specific postural and locomotor changes evoked in awake, freely moving intact cats by stimulating the brainstem. Brain Res. 505, 66-74. doi: 10.1016/0006-8993(89)90116-9

Motta, S., Goto, M., Gouveia, F., Baldo, M., Canteras, N., and Swanson, L. (2009). Dissecting the brain's fear system reveals the hypothalamus is critical for responding in subordinate conspecific intruders. Proc. Natl. Acad. Sci. U.S.A. 106, 4870-4875. doi: 10.1073/pnas.0900939106

Mullins, O., Hackett, J., Buchanan, J., and Friesen, O. (2011). Neuronal control of swimming behavior: comparison of vertebrate and invertebrate model systems. Prog. Neurobiol. 93, 244-269. doi: 10.1016/j.pneurobio.2010.11.001

Muthuraju, S., Talbot, T., and Brandão, M. (2016). Dopamine $\mathrm{D}_{2}$ receptors regulate unconditioned fear in deep layers of the superior colliculus and dorsal periaqueductal gray. Behav. Brain Res. 297, 116-123. doi: 10.1016/j.bbr.2015.10.005

Nagata, T., and Hayashi, Y. (1984). The visual field representation of the rat ventral lateral geniculate nucleus. J. Comp. Neurol. 227, 582-588. doi: $10.1002 / \mathrm{cne} .902270409$

Nicola, S. (2007). The nucleus accumbens as part of a basal ganglia action selection circuit. Psychopharmacology 191, 521-550. doi: 10.1007/s00213-006-0510-4

Noga, B. R., Kettler, J., and Jordan, L. M. (1988). Locomotion produced in mesencephalic cats by injections of putative transmitter substances and antagonists into the medial reticular formation and the pontomedullary locomotor strip. J. Neurosci. 8, 2074-2086.

Noga, B. R., Kriellaars, D. J., Brownstone, R. M., and Jordan, L. M. (2003). Mechanism for activation of locomotor centers in the spinal cord by stimulation of the mesencephalic locomotor region. J. Neurophysiol. 90, 1464-1478. doi: 10.1152/jn.00034.2003

Noga, B., Sanchez, F., Villamil, L., O’Toole, C., Kasicki, S., Olszewski, M., et al. (2017). LFP oscillations in the mesencephalic locomotor region during voluntary locomotion. Front. Neural Circuit 11:34. doi: 10.3389/fncir.2017.00034

Noga, B. R., Turkson, R. P., Xie, S., Taberner, A., Pinzon, A., and Hentall, I. D. (2017). Monoamine release in the cat lumbar spinal cord during fictive locomotion evoked by the mesencephalic locomotor region. Front. Neural Circuits 11:59. doi: 10.3389/fncir.2017.00059

Norton, A., Jo, Y., Clark, E., Taylor, C., and Mizumori, S. (2011). Independent neural coding of reward and movement by pedunculopontine tegmental nucleus neurons in freely navigating rats. Eur. J. Neurosci. 33, 1885-1896. doi: 10.1111/j.1460-9568.2011.07649.x

Oka, T., Tsumori, T., Yokota, S., and Yasui, Y. (2008). Neuroanatomical and neurochemical organization of projections from the central amygdaloid nucleus to the nucleus retroambiguus via the periaqueductal gray in the rat. Neurosci. Res. 62, 286-298. doi: 10.1016/j.neures.2008.10.004

Olmstead, M. C., and Franklin, K. B. (1994). Lesions of the pedunculopontine tegmental nucleus abolish catalepsy and locomotor depression induced by morphine. Brain Res. 662, 134-140. doi: 10.1016/0006-8993(94)90805-2

Olson, G., and Krasne, F. (1981). The crayfish lateral giants as command neurons for escape behavior. Brain Res. 214, 89-100. doi: 10.1016/0006-8993(81)90440-6

Olszewski, J., and Baxter, D. (1954). Cytoarchitecture of the Human Brain Stem. New York, NY: Basle: S. Karger.

Ondo, W. G., He, Y., Rajasekaran, S., and Le, W. D. (2000). Clinical correlates of 6-hydroxydopamine injections into A11 dopaminergic neurons in rats: a possible model for restless legs syndrome. Mov. Disord. 15, 154-158. doi: 10.1002/1531-8257(200001)15:1<154::AID-MDS1025>3.0.CO;2-Q

Pahapill, P., and Lozano, A. (2000). The pedunculopontine nucleus and Parkinson's disease. Brain 123, 1767-1783. doi: 10.1093/brain/123.9.1767

Palmiter, R. (2008). Dopamine signaling in the dorsal striatum is essential for motivated behaviors. Ann. N.Y. Acad. Sci. 1129, 35-46. doi: 10.1196/annals.1417.003

Pan, W.-X., and Hyland, B. (2005). Pedunculopontine tegmental nucleus controls conditioned responses of midbrain dopamine neurons in behaving rats. J. Neurosci. 25, 4725-4732. doi: 10.1523/JNEUROSCI.0277-05.2005
Parkinson, J. A., Cardinal, R. N., and Everitt, B. J. (2000). Limbic corticalventral striatal systems underlying appetitive conditioning. Prog. Brain Res. 126, 263-285. doi: 10.1016/S0079-6123(00)26019-6

Paxinos, G., and Franklin, K. B. (2008). The Mouse Brain in Stereotaxic Coordinates, Compact, Third Edition: The Coronal Plates and Diagrams, $3 \mathrm{rd}$ Edn. New York, NY: Elsevier Publishing.

Perreault, M. C., Drew, T., and Rossignol, S. (1993). Activity of medullary reticulospinal neurons during fictive locomotion. J. Neurophysiol. 69, 2232-2247.

Perrins, R., Walford, A., and Roberts, A. (2002). Sensory activation and role of inhibitory reticulospinal neurons that stop swimming in hatchling frog tadpoles. J. Neurosci. 22, 4229-4240.

Peterson, B. W., Pitts, N. G., and Fukushima (1979). Reticulospinal connections with limb and axial motoneurons. Exp. Brain Res. 36, 1-20. doi: 10.1007/BF00238464

Petras, J. M. (1967). Cortical, tectal and tegmental fiber connections in the spinal cord of the cat. Brain Res. 6, 275-324. doi: 10.1016/0006-8993(67)90196-5

Petrovich, G. D. (2011). Learning and the motivation to eat: forebrain circuitry. Physiol. Behav. 104, 582-589. doi: 10.1016/j.physbeh.2011.04.059

Petrovich, G. D., Risold, P. Y., and Swanson, L. W. (1996). Organization of projections from the basomedial nucleus of the amygdala: a PHAL study in the rat. J. Comp. Neurol. 374, 387-420. doi: 10.1002/(SICI)1096-9861(19961021)374:3<387::AID-CNE6>3.0.CO;2-Y

Peyron, C., Tighe, D. K., van den Pol, A. N., de Lecea, L., Heller, H. C., Sutcliffe, J. C., et al. (1998). Neurons containing hypocretin (orexin) project to multiple neuronal systems. J. Neurosci. 18, 9996-10015.

Phelps, E., and LeDoux, J. (2005). Contributions of the amygdala to emotion processing: from animal models to human behavior. Neuron 48, 175-187. doi: 10.1016/j.neuron.2005.09.025

Picton, L., Nascimento, F., Broadhead, M., Sillar, K., and Miles, G. (2017). Sodium pumps mediate activity-dependent changes in mammalian motor networks. J. Neurosci. 37, 906-921. doi: 10.1523/JNEUROSCI.2005-16.2016

Qu, S., Le, W., Zhang, X., Xie, W., Zhang, A., and Ondo, W. (2007). Locomotion is increased in all-lesioned mice with iron deprivation: a possible animal model for restless legs syndrome. J. Neuropathol. Exp. Neurol. 66, 383-388. doi: 10.1097/nen.0b013e3180517b5f

Richard, J., and Berridge, K. (2011). Nucleus accumbens dopamine/glutamate interaction switches modes to generate desire versus dread: D1 alone for appetitive eating but D1 and D2 together for fear. J. Neurosci. 31, 12866-12879. doi: 10.1523/JNEUROSCI.1339-11.2011

Roberts, W. W., and Carey, R. J. (1965). Rewarding effect of performance of gnawing aroused by hypothalamic stimulation in the rat. J. Comp. Physiol. Psychol. 59, 317-324. doi: 10.1037/h0022030

Roitman, M., Wheeler, R., and Carelli, R. (2005). Nucleus accumbens neurons are innately tuned for rewarding and aversive taste stimuli, encode their predictors, and are linked to motor output. Neuron 45, 587-597. doi: 10.1016/j.neuron.2004.12.055

Rolland, A.-S. S., Tandé, D., Herrero, M.-T. T., Luquin, M.-R. R., VazquezClaverie, M., Karachi, C., et al. (2009). Evidence for a dopaminergic innervation of the pedunculopontine nucleus in monkeys, and its drastic reduction after MPTP intoxication. J. Neurochem. 110, 1321-1329. doi: 10.1111/j.1471-4159.2009.06220.x

Roseberry, T. K., Lee, A. M., Lalive, A. L., Wilbrecht, L., Bonci, A., and Kreitzer, A. C. (2016). Cell-type-specific control of brainstem locomotor circuits by basal ganglia. Cell 164, 526-537. doi: 10.1016/j.cell.2015.12.037

Roseberry, T., and Kreitzer, A. (2017). Neural circuitry for behavioural arrest. Philos. Trans. R. Soc. B 372:20160197. doi: 10.1098/rstb.2016.0197

Ross, G. S., and Sinnamon, H. M. (1984). Forelimb and hindlimb stepping by the anesthetized rat elicited by electrical stimulation of the pons and medulla. Physiol. Behav. 33, 201-208. doi: 10.1016/0031-9384(84)90100-8

Rossignol, S., Dubuc, R., and Gossard, J.-P. (2006). Dynamic sensorimotor interactions in locomotion. Physiol. Rev. 86, 89-154. doi: 10.1152/physrev.00028.2005

Ryczko, D., Cone, J., Alpert, M., Goetz, L., Auclair, F., Dubé, C., et al. (2016). A descending dopamine pathway conserved from basal vertebrates to mammals. Proc. Natl. Acad. Sci. U.S.A. 113, E2440-E2449. doi: 10.1073/pnas.1600684113

Ryczko, D., and Dubuc, R. (2013). The multifunctional mesencephalic locomotor region. Curr. Pharm. Des. 19, 4448-4470. doi: 10.2174/1381612811319240011 
Ryczko, D., and Dubuc, R. (2017). Dopamine and the brainstem locomotor networks: from lamprey to human. Front. Neurosci. 11:295. doi: 10.3389/fnins.2017.00295

Ryczko, D., Grätsch, S., Auclair, F., Dubé, C., Bergeron, S., Alpert, M. H., et al. (2013). Forebrain dopamine neurons project down to a brainstem region controlling locomotion. Proc. Natl. Acad. Sci. U.S.A. 110, E3235-E3242. doi: 10.1073/pnas.1301125110

Sah, P., Faber, E., Armentia, L. M., and Power, J. (2003). The amygdaloid complex: anatomy and physiology. Physiol. Rev. 83, 803-834. doi: 10.1152/physrev.00002.2003

Sahibzada, N., Dean, P., and Redgrave, P. (1986). Movements resembling orientation or avoidance elicited by electrical stimulation of the superior colliculus in rats. J. Neurosci. 6, 723-733.

Sakurai, T. (2005). The Orexin/Hypocretin System. Totowa, NJ: Humana Press.

Sakurai, T., Amemiya, A., Ishii, M., Matsuzaki, I., Chemelli, R. M., Tanaka, H., et al. (1998). Orexins and orexin receptors: a family of hypothalamic neuropeptides and $\mathrm{G}$ protein-coupled receptors that regulate feeding behavior. Cell 92, 573-585. doi: 10.1016/S0092-8674(00)80949-6

Salgado, S., and Kaplitt, M. G. (2015). The nucleus accumbens: a comprehensive review. Stereot. Funct. Neuros 93, 75-93. doi: 10.1159/000368279

Saper, C. B. (2006). Staying awake for dinner: hypothalamic integration of sleep, feeding, and circadian rhythms. Prog. Brain Res. 153, 243-252. doi: 10.1016/S0079-6123(06)53014-6

Sar, M., Stumpf, W., Miller, R., Chang, K., and Cuatrecasas, P. (1978). Immunohistochemical localization of enkephalin in rat brain and spinal cord. J. Comp. Neurol. 182, 17-37. doi: 10.1002/cne.901820103

Sara, S. (2009). The locus coeruleus and noradrenergic modulation of cognition. Nat. Rev. Neurosci. 10, 211-223. doi: 10.1038/nrn2573

Sato, M., Ito, M., Nagase, M., Sugimura, Y., Takahashi, Y., Watabe, A., et al. (2015). The lateral parabrachial nucleus is actively involved in the acquisition of fear memory in mice. Mol. Brain 8, 1-15. doi: 10.1186/s13041-015-0108-Z

Satoda, T., Matsumoto, H., Zhou, L., Rose, P. K., and Richmond, F. J. (2002). Mesencephalic projections to the first cervical segment in the cat. Exp. Brain Res. 144, 397-413. doi: 10.1007/s00221-002-1047-3

Scarnati, E., Campana, E., and Pacitti, C. (1984). Pedunculopontine-evoked excitation of substantia nigra neurons in the rat. Brain Res. 304, 351-361. doi: 10.1016/0006-8993(84)90339-1

Scarnati, E., Proia, A., Di Loreto, S., and Pacitti, C. (1987). The reciprocal electrophysiological influence between the nucleus tegmenti pedunculopontinus and the substantia nigra in normal and decorticated rats. Brain Res. 423, 116-124. doi: 10.1016/0006-8993(87)90831-6

Schaltenbrand, G., and Wahren, W. (1977). Atlas for Stereotaxy of the Human Brain. Stuttgart; New York, NY: Thieme.

Sébille, S. B., Belaid, H., Philippe, A.-C. C., André, A., Lau, B., François, C., et al. (2017). Anatomical evidence for functional diversity in the mesencephalic locomotor region of primates. Neuroimage 147, 66-78. doi: 10.1016/j.neuroimage.2016.12.011

Semba, K., and Fibiger, H. C. (1992). Afferent connections of the laterodorsal and the pedunculopontine tegmental nuclei in the rat: a retro- and antero-grade transport and immunohistochemical study. J. Comp. Neurol. 323, 387-410. doi: $10.1002 /$ cne. 903230307

Sharples, S. A. (2017). Dopamine pumping up spinal locomotor network function. J. Neurosci. 37, 3103-3105. doi: 10.1523/JNEUROSCI.0019-17.2017

Sharples, S. A., and Whelan, P. J. (2017). Modulation of rhythmic activity in mammalian spinal networks is dependent on excitability state. eNeuro 4:ENEURO.0368-16.2017. doi: 10.1523/ENEURO.0368-16.2017

Sharples, S. A., Humphreys, J. M., Jensen, A. M., Dhoopar, S., Delaloye, N., Clemens, S., et al. (2015). Dopaminergic modulation of locomotor network activity in the neonatal mouse spinal cord. J. Neurophysiol. 113, 2500-2010. doi: $10.1152 /$ jn.00849.2014

Sharples, S. A., Koblinger, K., Humphreys, J. M., and Whelan, P. J. (2014). Dopamine: a parallel pathway for the modulation of spinal locomotor networks. Front. Neural Circuits 8:55. doi: 10.3389/fncir.2014. 00055

Sherman, D., Fuller, P., Marcus, J., Yu, J., Zhang, P., Chamberlin, N., et al. (2015). Anatomical location of the mesencephalic locomotor region and its possible role in locomotion, posture, cataplexy, and parkinsonism. Front. Neurol. 6:140. doi: 10.3389/fneur.2015.00140
Shik, M. L., and Orlovsky, G. N. (1976). Neurophysiology of locomotor automatism. Physiol. Rev. 56, 465-501.

Shik, M. L., Severin, F. V., and Orlovsky, G. N. (1969). Control of walking and running by means of electrical stimulation of the mesencephalon. Electr. Clin. Neurol. 26:549.

Siegel, J., and Boehmer, L. (2006). Narcolepsy and the hypocretin systemwhere motion meets emotion. Nat. Clin. Pract. Neurol. 2, 548-556. doi: $10.1038 /$ ncpneuro0300

Sinnamon, H. (1993). Preoptic and hypothalamic neurons and the initiation of locomotion in the anesthetized rat. Prog. Neurobiol. 41, 323-344. doi: 10.1016/0301-0082(93)90003-B

Sinnamon, H. M., Lee, S. H., Adams, D. B., and Stopford, C. K. (1984). Locomotor stepping elicited by electrical stimulation of the lateral hypothalamus requires an ipsilateral descending pathway. Physiol. Behav. 33, 209-215. doi: 10.1016/0031-9384(84)90101-X

Sinnamon, H., and Stopford, K. (1987). Locomotion elicited by lateral hypothalamic stimulation in the anesthetized rat does not require the dorsal midbrain. Brain Res. 402, 78-86. doi: 10.1016/0006-8993(87)91049-3

Sirota, M. G., and Shik, M. L. (1973). Locomotion of the cat on stimulation of the mesencephalon. Fiziol. Zhurnal Sssr Imeni M Sechenova 59, 1314-1321.

Skagerberg, G., and Lindvall, O. (1985). Organization of diencephalic dopamine neurones projecting to the spinal cord in the rat. Brain Res. 342, 340-351. doi: 10.1016/0006-8993(85)91134-5

Skinner, R. D., and Garcia-Rill, E. (1984). The mesencephalic locomotor region (MLR) in the rat. Brain Res. 323, 385-389.

Skinner, R. D., Kinjo, N., Henderson, V., and Garcia-Rill, E. (1990). Locomotor projections from the pedunculopontine nucleus to the spinai cord. Neuroreport 1, 183-186. doi: 10.1097/00001756-199011000-00001

Sparks, D. L. (1986). Translation of sensory signals into commands for control of saccadic eye movements: role of primate superior colliculus. Physiol. Rev. 66, $118-171$.

Steeves, J., and Jordan, L. (1980). Localization of a descending pathway in the spinal cord which is necessary for controlled treadmill locomotion. Neurosci. Lett. 20, 283-288. doi: 10.1016/0304-3940(80)90161-5

Stefanik, M., Kupchik, Y., and Kalivas, P. (2016). Optogenetic inhibition of cortical afferents in the nucleus accumbens simultaneously prevents cueinduced transient synaptic potentiation and cocaine-seeking behavior. Brain Struct. Funct. 221, 1681-1689. doi: 10.1007/s00429-015-0997-8

Stefanik, M., Kupchik, Y., Brown, R., and Kalivas, P. (2013). Optogenetic evidence that pallidal projections, not nigral projections, from the nucleus accumbens core are necessary for reinstating cocaine seeking. J. Neurosci. 33, 13654-13662. doi: 10.1523/JNEUROSCI.1570-13.2013

Steininger, T. L., Rye, D. B., and Wainer, B. H. (1992). Afferent projections to the cholinergic pedunculopontine tegmental nucleus and adjacent midbrain extrapyramidal area in the albino rat. I. Retrograde tracing studies. J. Comp. Neurol. 321, 515-543. doi: 10.1002/cne.903210403

Stoyanova, I. I., Rutten, W. L., and le Feber, J. (2010). Orexin-A and orexin-B during the postnatal development of the rat brain. Cell. Mol. Neurobiol. 30, 81-89. doi: 10.1007/s10571-009-9433-z

Stuber, G. D., and Wise, R. A. (2016). Lateral hypothalamic circuits for feeding and reward. Nat. Neurosci. 19, 198-205. doi: 10.1038/nn.4220

Surmeier, J., Ding, J., Day, M., Wang, Z., and Shen, W. (2007). D1 and D2 dopamine-receptor modulation of striatal glutamatergic signaling in striatal medium spiny neurons. Trends Neurosci. 30, 228-235. doi: 10.1016/j.tins.2007.03.008

Swanson, L. W. (2000). Cerebral hemisphere regulation of motivated behavior. Brain Res. 886, 113-164. doi: 10.1016/S0006-8993(00)02905-X

Swanson, L., Sanchez-Watts, G., and Watts, A. (2005). Comparison of melaninconcentrating hormone and hypocretin/orexin mRNA expression patterns in a new parceling scheme of the lateral hypothalamic zone. Neurosci. Lett. 387, 80-84. doi: 10.1016/j.neulet.2005.06.066

Szokol, K., Glover, J., and Perreault, M.-C. (2011). Organization of functional synaptic connections between medullary reticulospinal neurons and lumbar descending commissural interneurons in the neonatal mouse. J. Neurosci. 31, 4731-4742. doi: 10.1523/JNEUROSCI.5486-10.2011

Takakusaki, K., Habaguchi, T., Ohtinata-Sugimoto, J., Saitoh, K., and Sakamoto, T. (2003). Basal ganglia efferents to the brainstem centers controlling postural muscle tone and locomotion: a new concept for understanding 
motor disorders in basal ganglia dysfunction. Neuroscience 119, 293-308. doi: 10.1016/S0306-4522(03)00095-2

Takakusaki, K., Takahashi, K., Saitoh, K., Harada, H., Okumura, T., Kayama, Y., et al. (2005). Orexinergic projections to the cat midbrain mediate alternation of emotional behavioural states from locomotion to cataplexy. J. Physiol. 568, 1003-1020. doi: 10.1113/jphysiol.2005.085829

Tay, T., Ronneberger, O., Ryu, S., Nitschke, R., and Driever, W. (2011). Comprehensive catecholaminergic projectome analysis reveals single-neuron integration of zebrafish ascending and descending dopaminergic systems. Nat. Commun. 2:171. doi: 10.1038/ncomms1171

Thakkar, M. M., Ramesh, V., Strecker, R. E., and McCarley, R. W. (2001). Microdialysis perfusion of orexin-A in the basal forebrain increases wakefulness in freely behaving rats. Arch. Ital. Biol. 139, 313-328. doi: 10.4449/aib.v139i3.506

Thankachan, S., Fuller, P. M., and Lu, J. (2012). Movement- and behavioral state-dependent activity of pontine reticulospinal neurons. Neuroscience 221, 125-139. doi: 10.1016/j.neuroscience.2012.06.069

Tovote, P., Esposito, M., Botta, P., Chaudun, F., Fadok, J., Markovic, M., et al. (2016). Midbrain circuits for defensive behaviour. Nature 534, 206-212. doi: 10.1038/nature17996

Utter, A., and Basso, M. (2008). The basal ganglia: an overview of circuits and function. Neurosci. Biobehav. Rev. 32, 333-342. doi: 10.1016/j.neubiorev.2006.11.003

Valenstein, E. (1971). Channeling of responses elicited by hypothalamic stimulation. J. Psychiatr. Res. 8, 335-344. doi: 10.1016/0022-3956(71)90029-X

Valenstein, E., Cox, V., and Kakolewski, J. (1970). Reexamination of the role of the hypothalamus in motivation. Psychol. Rev. 77:16. doi: 10.1037/h0028581

Vianna, D. M. L., Landeira-Fernandez, J., and Brandão, M. L. (2001). Dorsolateral and ventral regions of the periaqueductal gray matter are involved in distinct types of fear. Neurosci. Biobehav. Rev. 25, 711-719. doi: 10.1016/S0149-7634(01)00052-5

Vincent, S. R. (2000). The ascending reticular activating system-from aminergic neurons to nitric oxide. J. Chem. Neuroanat. 18, 23-30. doi: 10.1016/S0891-0618(99)00048-4

Wagner, C. K., Eaton, M. J., Moore, K. E., and Lookingland, K. J. (1995). Efferent projections from the region of the medial zona incerta containing A13 dopaminergic neurons: a PHA-L anterograde tract-tracing study in the rat. Brain Res. 677, 229-237. doi: 10.1016/0006-8993(95)00128-D

Wall, N., De La Parra, M., Callaway, E., and Kreitzer, A. (2013). Differential innervation of direct- and indirect-pathway striatal projection neurons. Neuron 79, 347-360. doi: 10.1016/j.neuron.2013.05.014

Waller, W. H. (1940). Progression movements elicited by subthalamic stimulation. J. Neurophysiol. 3, 300-307.

Wannier, T., Orlovsky, G., and Grillner, S. (1995). Reticulospinal neurones provide monosynaptic glycinergic inhibition of spinal neurones in lamprey. Neuroreport 6, 1597. doi: 10.1097/00001756-199508000-00003
Whelan, P. J. (1996). Control of locomotion in the decerebrate cat. Prog. Neurobiol. 49, 481-515. doi: 10.1016/0301-0082(96)00028-7

Whishaw, I., Alaverdashvili, M., and Kolb, B. (2008). The problem of relating plasticity and skilled reaching after motor cortex stroke in the rat. Behav. Brain Res. 192, 124-136. doi: 10.1016/j.bbr.2007.12.026

Wilensky, A., Schafe, G., Kristensen, M., and LeDoux, J. (2006). Rethinking the fear circuit: the central nucleus of the amygdala is required for the acquisition, consolidation, and expression of pavlovian fear conditioning. J. Neurosci. 26, 12387-12396. doi: 10.1523/JNEUROSCI.4316-06.2006

Wullimann, M. F. (2014). Ancestry of basal ganglia circuits: new evidence in teleosts. J. Comp. Neurol. 522, 2013-2018. doi: 10.1002/cne.23525

Xiang, H.-B. B., Zhu, W.-Z. Z., Guan, X.-H. H., and Ye, D.-W. W. (2013). The cuneiform nucleus may be involved in the regulation of skeletal muscle tone by motor pathway: a virally mediated trans-synaptic tracing study in surgically sympathectomized mice. Brain 136:e251. doi: 10.1093/brain/ awt 123

Xiao, C., Cho, J., Zhou, C., Treweek, J., Chan, K., McKinney, S., et al. (2016). Cholinergic mesopontine signals govern locomotion and reward through dissociable midbrain pathways. Neuron 90, 333-347. doi: 10.1016/j.neuron.2016.03.028

Yamamoto, K., and Vernier, P. (2011). The evolution of dopamine systems in chordates. Front. Neuroanat. 5:21. doi: 10.3389/fnana.2011.00021

Yeomans, J. S., and Frankland, P. W. (1995). The acoustic startle reflex: neurons and connections. Brain Res. Rev. 21, 301-314. doi: 10.1016/0165-0173(96)00004-5

Yeomans, J., Li, L., Scott, B., and Frankland, P. (2002). Tactile, acoustic and vestibular systems sum to elicit the startle reflex. Neurosci. Biobehav. Rev. 26, 1-11. doi: 10.1016/S0149-7634(01)00057-4

Yilmaz, M., and Meister, M. (2013). Rapid innate defensive responses of mice to looming visual stimuli. Curr. Biol. 23, 2011-2015. doi: 10.1016/j.cub.2013.08.015

Zweig, R., Jankel, W., Hedreen, J., Mayeux, R., and Price, D. (1989). The pedunculopontine nucleus in Parkinson's disease. Ann. Neurol. 26, 41-46. doi: 10.1002/ana.410260106

Conflict of Interest Statement: The authors declare that the research was conducted in the absence of any commercial or financial relationships that could be construed as a potential conflict of interest.

Copyright (C) 2017 Kim, Sharma, Sharples, Mayr, Kwok and Whelan. This is an open-access article distributed under the terms of the Creative Commons Attribution License (CC BY). The use, distribution or reproduction in other forums is permitted, provided the original author(s) or licensor are credited and that the original publication in this journal is cited, in accordance with accepted academic practice. No use, distribution or reproduction is permitted which does not comply with these terms. 